\title{
Experimental investigation on synthesis, characterization, stability, thermo-physical properties and rheological behavior of MWCNTs-kapok seed oil based nanofluid
} \author{
Cornelius B. Bavoh ${ }^{c}$, Wajid Ur Rehman ${ }^{d}$, Alfredo Guardo ${ }^{b}$

\footnotetext{
${ }^{a}$ Department of Chemical Engineering, NFC Institute of Engineering and Fertilizer Research Faisalabad, Pakistan

${ }^{b}$ Department of Chemical Engineering, Universitat Politecnica de Catalunya, Spain

c Department of Chemical Engineering, Universiti Teknologi Petronas, Malaysia

${ }^{d}$ Institute of Chemical Sciences, University of Peshawar, Pakistan
}

Ayesha Hameed a , Ahmad Mukhtar a , Umar Shafiq a , Masooma Qizilbash ${ }^{\text {b }}$, Muhammad Saad Khan ${ }^{\mathrm{c}, *}$, Tazien Rashid ${ }^{\text {a }}$

\section{ABSTRACT}

Several researchers devoted their efforts for the thermal conductivity enhancement of Carbon Nanotubes (CNTs) based nanofluids as CNTs have excellent thermal properties. However, limited research is reported on the detailed thermo-physical properties of CNTs and oil based nanofluids. In this work, the one-step method synthesis of a new MWCNTs-Kapok seed oil based nanofluid at constant nanoparticle concentration ( 0.1 wt./wt.) is reported. The nanofluid is characterized by FESEM, FTIR, visual stability analysis and thermophysical properties are experimentally measured. The viscosity found in the range of $(0.049-10.101 \mathrm{~Pa} \cdot \mathrm{s})$, the thermal conductivity of $(0.165-0.207 \mathrm{~W} / \mathrm{m} \cdot \mathrm{K})$ and enhancement of thermal conductivity (6.1538\%) were observed. Moreover, the viscosity decreases, and thermal conductivity increases with an increase in temperature. The experimentally obtained data are found in agreement with existing models and modified correlations. The rheological behavior showed that nanofluid is non-Newtonian in nature and exhibiting shear thinning or pseudo plastic behavior.

\section{Introduction}

Recent advances in thermal science and engineering involve the enhancement of heat transfer for their diverse industrial applications in the field of chemical engineering, energy, aerospace, manufacturing, transportation, construction, information, automobile, biomedicine, environment, microelectronics, and nuclear power plants [1]. These advances make a keen interest to synthesize micro-scale based fluid flow devices, with ultrahigh specific surface area, high specific surface to volume ratio compared to conventional fluid flow based heat transfer systems [2]. For this purpose, the convection mode of heat transfer, the most significant mode of heat transfer has been extensively investigated for parametric effect on heat transfer performance. The limitation in the design and development to of energy-efficient heat transfer system in convective heat transfer mode are the low thermal conductivity and rheological behavior of conventional heat transfer fluids such as water, oil, and ethylene glycol [3]. An effective way to enhance the thermal conductivity of heat transfer fluids is the use of nanofluids. Nanofluids are engineered stable and dilute liquid suspension of nanosized particles (b100 nm) such as metal particles, carbon nanofibers, carbon nanotubes, and rods into traditional heat transfer fluids such as water, engine oil, and ethylene glycol in a small quantity (b1 vol\%) [3-5].

In past decades, most of the research efforts have been paid to the development of novel nanofluids because of their excellent thermal properties [6],wetting, spreading, antibacterial activity [7-11], no flammability and toxicity [12], electrically non-conductive and highly stable for both stack and safety efficiency, minimum volume requirements for cooling or heating purpose, favorable viscosity for pumping at a specific conditions, material compatibility with the heat transfer equipment material, ability to accept hydrogen gas in solution without any degradation, ability to sustain in high voltage fields, no problem of erosion, corrosion, and plugging in microchannel $(0.3 \mathrm{~nm})$, and avoiding of pressure drop in flow channels.

During last two decades, various nano-material in different forms (of disk, particle, tube, fiber, sheet, etc.) including metals [13], nitrides [14], diamonds [15], carbon nanotubes [16,17], oxides [18], carbon black [19], carbon nanofibers [20], graphene [21], graphene oxide [21], graphite black [22,23], and hybrid [24,25] have been utilized for the synthesis of nanofluids to enhance thermal performance. Among these materials, carbon-based materials especially carbon nanotubes found to be promising candidate because of its excellent thermal properties. 
Carbon nanotubes (CNTs), a wonder material, possess outstanding chemical, mechanical, thermal, electrical, and optical features have a wide range of applications in multidisciplinary fields such as materials science, aerospace, automotive, optical and energy conversion [26]. CNTs act like metals or semiconductors because of their high thermal and electrical conductivity. Due to remarkable properties, CNT can be used as polymer composite materials, as a diodes and transistors in Nanoelectronics, as a heat transfer medium in lithium-ion batteries, as electrochemical actuators and sensors in super-capacitors, and used in water desalination membranes due to their high chemical stability and high surface to volume ratio $[27,28]$.

Nanofluids can be synthesized via two different methods: one-step method and two-step method. The one-step method involves the single step dispersion of nanoparticle to base fluid while the two-step method involves the synthesis of nanoparticle in first step and its dispersion to base fluids in second step. One-step method is more feasible than two-step method for high stability and less nanoparticle sedimentation. Nanoparticles or nanopowder can be easily purchased from the market in one-step method [29].

To date, a number of nanofluids have been reported in literature i.e. CNTs such as water and antifreeze containing CNTs nanoparticles [30], S-SWNTs-water, L-SWNTs-water, [31,32], silver decorated CNTs-water [33], copper oxide surface modified CNTs-water nanoparticles [34], graphene based MWCNTs-ethylene glycol [35], hexylamine coolant modified MWCNTs-transformer oil [36], functionalized MWCNTs-ionic liquids [37], MWCNTs-imidazolium based ionic liquids [38], CNTs-deionized water [39], Fe304-MWCNTs-distilled water [40], CNTs- poly-alpha-olefin (PAO) [41], CuCNTs-deionized water and Au-CNTs-deionized water [42], Cu-MWCNTs-ethylene glycol-water [24], Al2O3-MWCNTswater [43], MWCNTs-Turbine Oil [44], MWCNTs-Engine Oil [45], MWCNTs-Mineral Oil [46], MWCNTs-Silicon Oil [47], CuO-EG-distilled water [48], Ag-SiC-water [49], and hybrid nanofluids [50].

Most of the reported literature focused on the individual properties of nanofluids and few of them reported the all thermo-physical and rheological properties. No doubt all these thermo-physical properties uniformly influence the overall heat transfer performance. Most of the reported data directs the experimental investigation on thermophysical properties of based on the different nanoparticles concentration in base fluids at room temperature and limited data is available on temperature dependency. While on the other side, the development of novel nanofluids with high stability and less nanoparticle sedimentation is still a major challenge in the commercialization of nanofluids.

The aim of this work is to synthesize and characterize the MWCNTs-Kapok Seed Oil based nanofluid via the one-step method. This study involves the experimental investigation of viscosity, thermal conductivity and rheological behavior at different temperatures $\left(25-65^{\circ} \mathrm{C}\right)$ and ultrasonication time $(1-6 \mathrm{~h})$ at constant nanoparticle concentration $(0.1$ wt./wt.). The experimentally measured thermophysical properties are compared and validated with the existing theoretical models.

\section{Materials and methods}

Kapok seed oil were collected from Bota Kannan, Perak, Malaysia. The MWCNTs were purchased from sigma-Aldrich (N98\% carbon basis, OD $\times \mathrm{L}=6-13 \mathrm{~nm} \times 2.5-20 \mu \mathrm{m}$ ) and used without any further procedure.

\subsection{Nanofluid preparation and characterization}

Kapok Seed Oil based MWCNTs nanofluids were formulated with dry MWCNTs (0.1 wt./wt.) and pure Kapok Seed Oil by using the so-called one-step method [51,52]. This method is used to prepare the nanofluids using the MWCNTs weight concentration of $0.1 \%$ at different temperatures $\left(30{ }^{\circ} \mathrm{C}, 45^{\circ} \mathrm{C}, 60^{\circ} \mathrm{C}, 75{ }^{\circ} \mathrm{C}\right.$, and $90{ }^{\circ} \mathrm{C}$ ). Mechanical mixing technique is applied to disperse the MWCNTs. An ultrasonic probe-type disrupter with the power (70\%) and pulse $(30 \%)$ is used to stabilize all nanofluids samples at six different ultrasonication time ranges (1-6 h). The ultrasonic probe-type disrupter gives a better dispersion of nanoparticles in the base fluid than bath-type ultrasonication. However, during the process, the temperature rises significantly due to disruption in agglomerates caused by the heat transfer through the ultrasonic waves. To address this issue, the nanofluids samples are ultra-sonicated with water bath cooling, Hashnin, HS 3005 N. A schematic illustration of the preparation of nanofluids used in many investigations [53-57] is shown in Fig. 1. The desired nanoparticles weight fractions and volume concentrations are calculated using 
Eq. (1) and Eq. (2) respectively $[58,59]$. The characterization of the prepared nanofluid is reported in our previous work [60].

$\phi=\frac{w \rho_{b f}}{\left(1-\frac{w}{100}\right) \rho_{n p}-\left(\frac{w}{100}\right) \rho_{b f}}$

$\phi=\frac{\left(\frac{m_{n p}}{\rho_{n p}}\right)}{\left(\frac{m_{n p}}{\rho_{n p}}\right)+\left(\frac{m_{b f}}{\rho_{b f}}\right)}$

where $\phi$ is the volume concentration, $w$ is the weight fraction, $\rho_{b f}$ is the density of base fluid, $\rho_{n p}$ is the density of nanoparticles, $m_{n p}$ is the weight of nanoparticles, and $m_{b f}$ is the weight of the base fluid.

Analytical methods are utilized to characterize the MWCNTs, kapok seed oil and nanofluid via field emission scanning electron microscopy (VPFESEM-Zeiss Supra55 VP), and Fourier transform infrared spectroscopy (ATR-FTIR) using Thermo Scientific Nicolet iS-10 FTIR spectrometer equipped with Attenuated Total Reflection (ATR) element of Smart iTX AR Diamond and Omnic 5.1 Software.

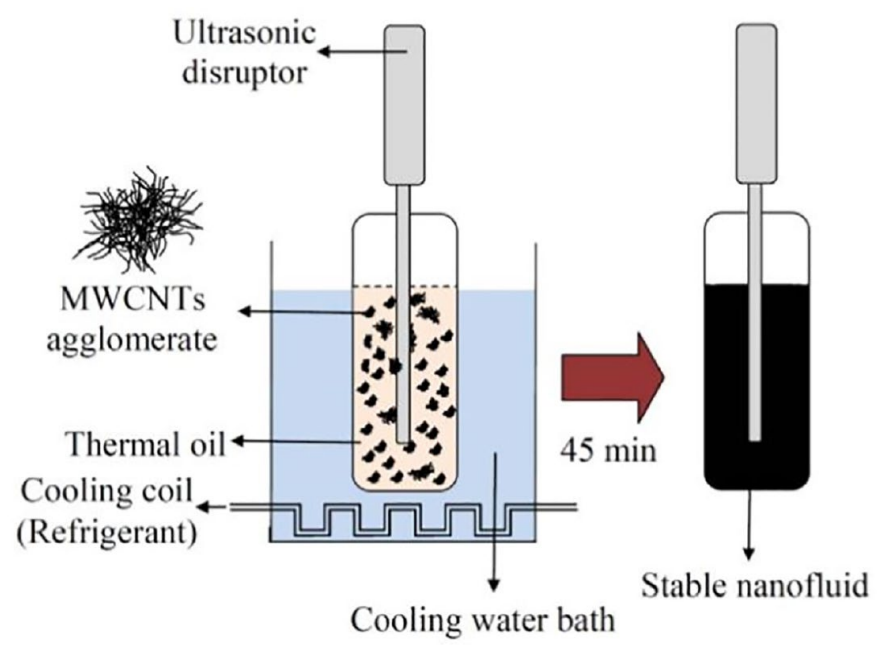

Fig. 1. A schematic diagram of the synthesis of MWCNTs-Kapok seed oil based nanofluid using ultrasonication homogenization.

\section{Results and discussions}

\subsection{Characterization of MWCNTs, kapok seed oil and nanofluid}

Field emission scanning electron microscopy (FESEM) is widely utilized to characterize the individual length of MWCNTs as well as surface morphological structure [61-65]. As shown in Fig. 2 (a \& b), the FESEM images at different magnification ( $1.29 \mathrm{~K}$ and $2.97 \mathrm{~K}$ ) provide an evidence that the acquired MWCNTs are found to be in the form of highly agglomeration and it is difficult to determine the individual particle size and morphology. This high agglomeration is one of the major cause of particle growth and instability of MWCNTs based nanofluids which can be overcome by using ultrasonication [66]. SEM provides an evidence that the MWCNTs powder exceeds the average agglomerate diameter of micron scale [54].

One of the most significant characterization techniques in the evaluation of MWCNTs characteristics is the microstructure-based investigation as shown in Fig. 3. The FESEM images of MWCNTs shown an obvious diameter of MWCNTs in the range of $15.79 \mathrm{~nm}$ to $19.21 \mathrm{~nm}$. The MWCNTs mostly contain on large fibers like tubes. The FESEM images also shown that the individual diameters of MWCNTs were not same however their individual lengths are uniform. A similar morphology of MWCNTs were observed by some researchers [67-69]. 


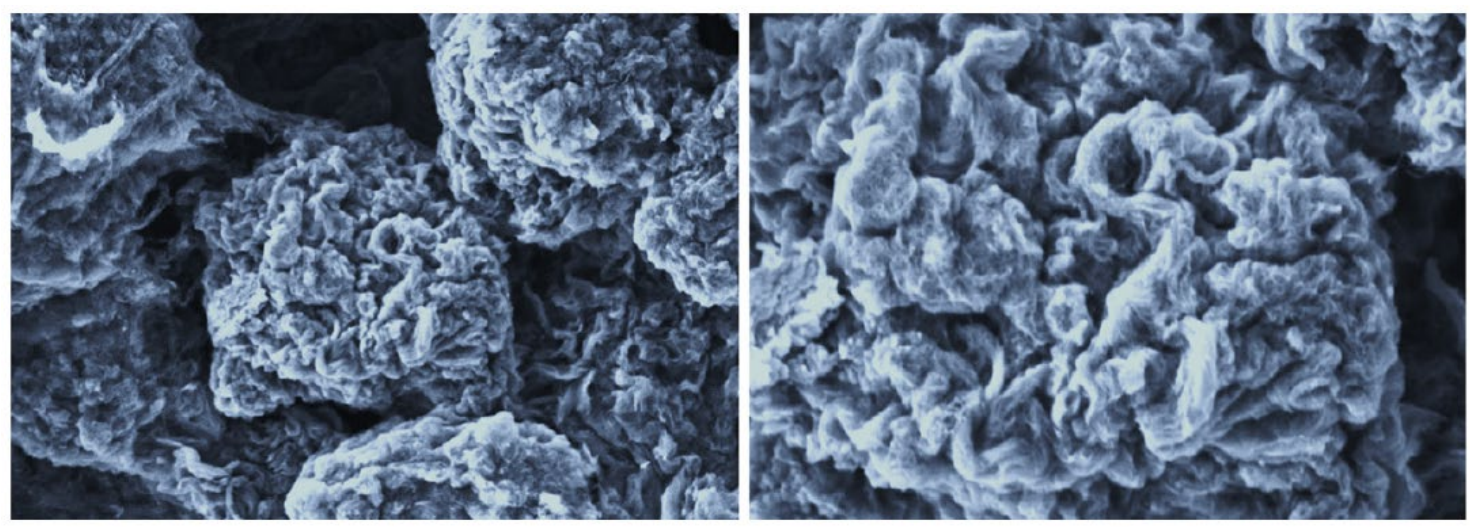

Fig. 2. FESEM images of MWCNTs at (a) $1.29 \mathrm{~K}$ (b) $2.97 \mathrm{~K}$ magnification.

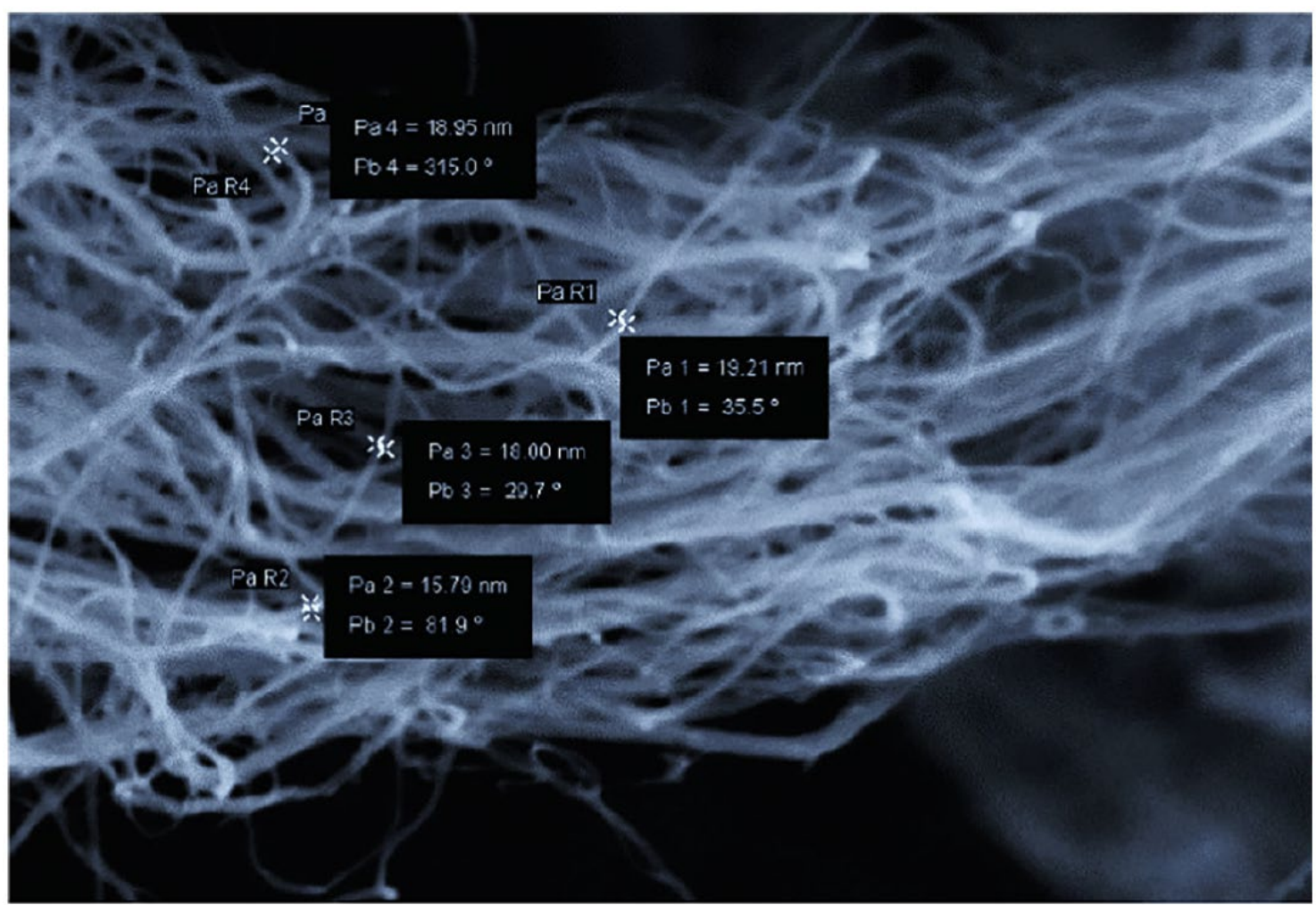

Fig. 3. FESEM images of MWCNTS.

The formation of new bonds and determination of functional groups is done by using FTIR technique. The FTIR analysis of kapok seed oil and MWCNTs-kapok seed oil based nanofluid is shown in Fig. 4. The FTIR spectrum indicates the typical features of absorption bonds corresponding to common molecules of triglyceride. The symmetrical and asymmetrical stretching vibration of methylene $\left(-\mathrm{CH}_{2}\right)$ at $1746 \mathrm{~cm}^{-1}$ can be related to the absorption due to ester carbonyl functional group present in triglycerides. The bending vibration of $\mathrm{CH}_{2}$ and $\mathrm{CH}_{3}$ aliphatic groups along with $\mathrm{CH}_{2}$ groups is shown at $1458 \mathrm{~cm}^{-1}$ and $1377 \mathrm{~cm}^{-1}$ respectively. Peaks around $1160 \mathrm{~cm}^{-1}$ may be related to the $\mathrm{C}-\mathrm{O}$ stretching, while peaks around $722 \mathrm{~cm}^{-1}$ may be due to the overlapping of methylene $\left(-\mathrm{CH}_{2}\right)$ rocking vibration and to the out of plane vibration is cis-disubstituted. 


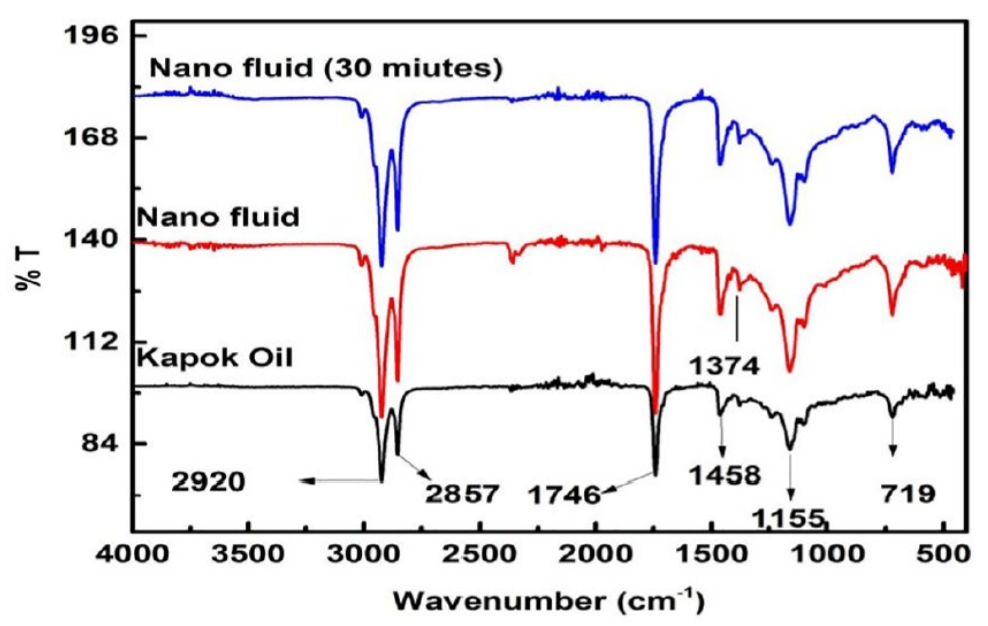

Fig. 4. FTIR images of kapok seed oil and MWCNTs-kapok seed oil based nanofluid.

\subsection{Stability of nanofluid}

The stability of dispersion in nanofluids plays a significant role in the commercialization of nanofluid for their diverse industrial applications. The high specific surface area and smaller size of nanoparticles lead to enhanced intermolecular forces on the surface of nanomaterials and attracts the particles from agglomerates. This phenomenon is well explained by the DLVO theory or colloidal particle theory [53]. The DLVO theory is essential for better understanding of electrostatic, magnetic, and van der walls forces. The instability of nanofluid is due to sedimentation of nanoparticles due to the gravitational force on nano-sized agglomerates and it can cause microchannel to affect the overall effective thermal conductivity and heat transfer performance of nanofluids in process equipment. Therefore, the better knowledge, understanding and interpretation of the intermolecular forces between nanoparticles and base fluid are significantly important towards the synthesis of stable nanofluids [70]. In our case, the sedimentation characteristics of nanofluids are investigated in a batch sedimentation apparatus using conventional visualization technique [57,70-72]. The photographs Fig. 5 are taken after an equal interval of times for MWCNTs-Kapok seed oil based nanofluid with nanoparticle concentration of $0.1 \mathrm{wt} \%$. An ultrasonic disruptor (probe-type) is used for the better dispersion of newly synthesized MWCNTs-Kapok seed oil based nanofluid samples for (1-6 h). The comparative visual analysis Fig. 5 showed that MWCNTs are found to be highly stable in kapok seed oil using this approach of mechanical mixing and MWCNTs did not settle for down for at least one month. These results clearly recommend that the mechanical technique of mixing (ultrasonication) is much better than chemical mixing techniques to prepared nanofluid with high dispersion stability.

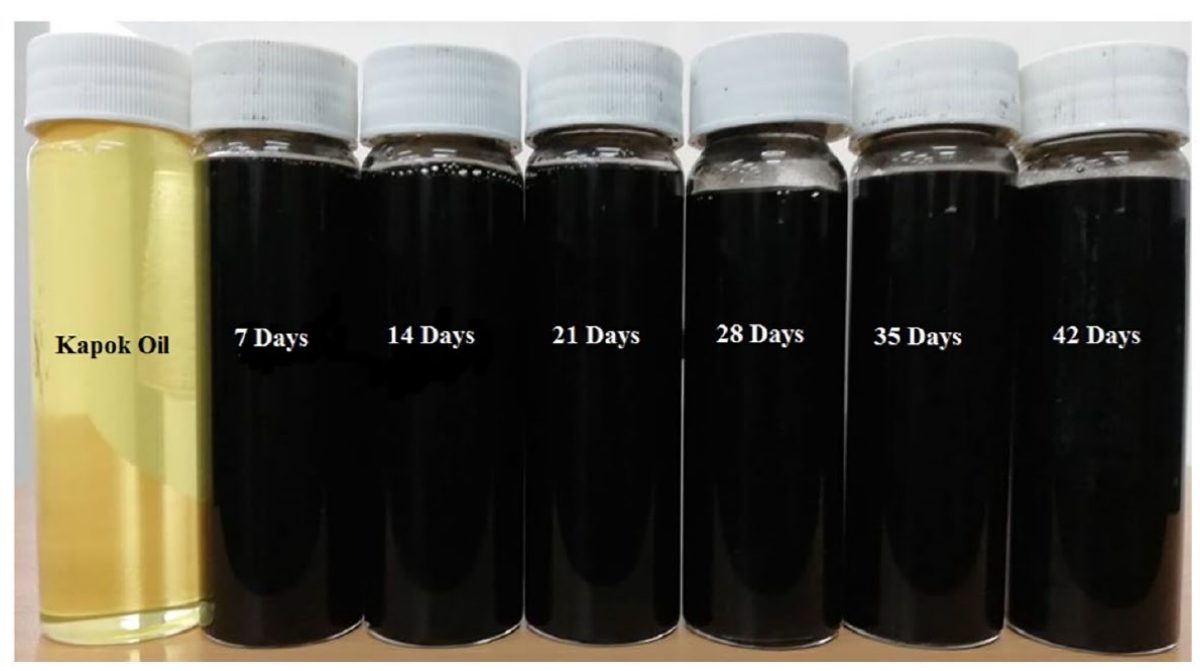

Fig. 5. Visual photographs of MWCNTs-Kapok seed oil based nanofluid samples after an interval of time. 


\subsection{Viscosity}

Viscosity is one of the most significant fluid properties and significantly important in the optimum design and operation of heat transfer equipment. High viscous nanofluids may arise considerable engineering problems due to high energy pumping equipment as well as mixing equipment [73]. Rotational rheometer, Anton Paar, MCR 102, is used to measure the effective viscosity of MWCNTs-Kapok Seed Oil based nanofluid as a function of temperature $\left(30-90{ }^{\circ} \mathrm{C}\right)$ and sonication time (1-6 h) at a constant shear rate of $\left(100 \mathrm{~s}^{-1}\right)$ and constant nanoparticle concentration (0.1 wt/wt\%). The typical behavior of effective viscosity as a function of temperature over different sonication time is shown in Fig. 6. The viscosity of nanofluid decreases non-linearly with the rise in temperature in all sonication time ranges as the rising in temperature diminish the intermolecular forces between the nanoparticles and base fluid [58]. This temperature-viscosity behavior shows high agreement with most of the previous work [74-76].

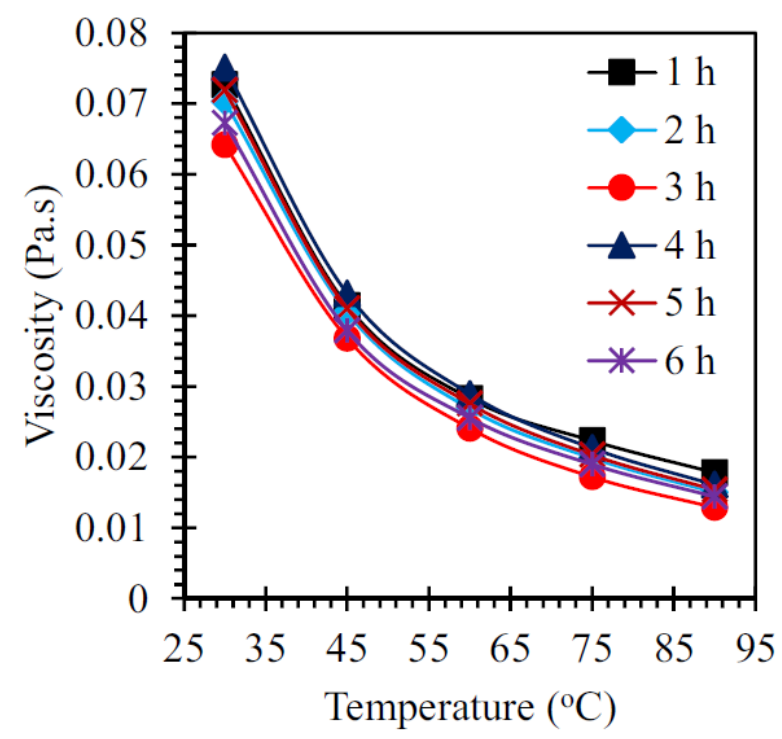

Fig. 6. Viscosity ofMWCNTs-Kapok Seed Oil based nanofluid at different temperature and ultrasonication time ranges.

It should be noted that there are many models available for the prediction of effective viscosity as a function of volume concentration without any temperature dependence consideration [77-80]. It should be mentioned that there are few studies associated with the investigation of temperature effect on viscosity of nanofluids.

Khanafer and Vafai [81] proposed a correlation Eq. (3) for the prediction of effective viscosity of Al2O3-water-based nanofluid as a function of temperature dependence which was followed by Suhaib Umer llyas [54] for the prediction of effective viscosity of MWCNTs and thermal oil based nanofluid. Sun and Teja [82] proposed a viscosity-temperature based correlation Eq. (4) for prediction of TiO2-Ethylene glycol based nanofluid. Kulkarni [83] investigated the temperature dependent rheological properties of copper oxide (CuO) and deionized (DI) water-based nanofluid and proposed a correlation Eq. (5) for the accurate estimation of the viscosity of nanofluids as a function of temperature and nanoparticles concentration.

$\mu_{n f}=-1.8231-\frac{0.0686}{T}+1.7235\left(1-\varphi_{p}\right)+3.329\left(1-\varphi_{p}\right)^{2}+136.7838\left(\frac{\left(1-\varphi_{p}\right)^{2}}{T^{2}}\right)-3.3263\left(1-\varphi_{p}\right)^{3}-2347.39\left(\frac{\left(1-\varphi_{p}\right)}{T^{3}}\right)$

$\ln \left(\mu_{n f}\right)=A+B \cdot 1000(T+C)$

$\mu_{n f}=A e^{\left(\frac{B}{T}+C \varphi\right)}$ 
In Eq. (3) temperature is in $\left({ }^{\circ} \mathrm{C}\right.$ ) and viscosity is in (Pa.s), in Eq. (4) temperature is in (K) and viscosity is in (mPa.s), and in Eq. (5) temperature is in (K) and viscosity is in (Pa.s). The interpolation of experimental data and predicted data from above three mentioned models is shown in Fig. 7. In above three models A, B, and C are constant curve fit parameters which are calculated based on regression analysis.
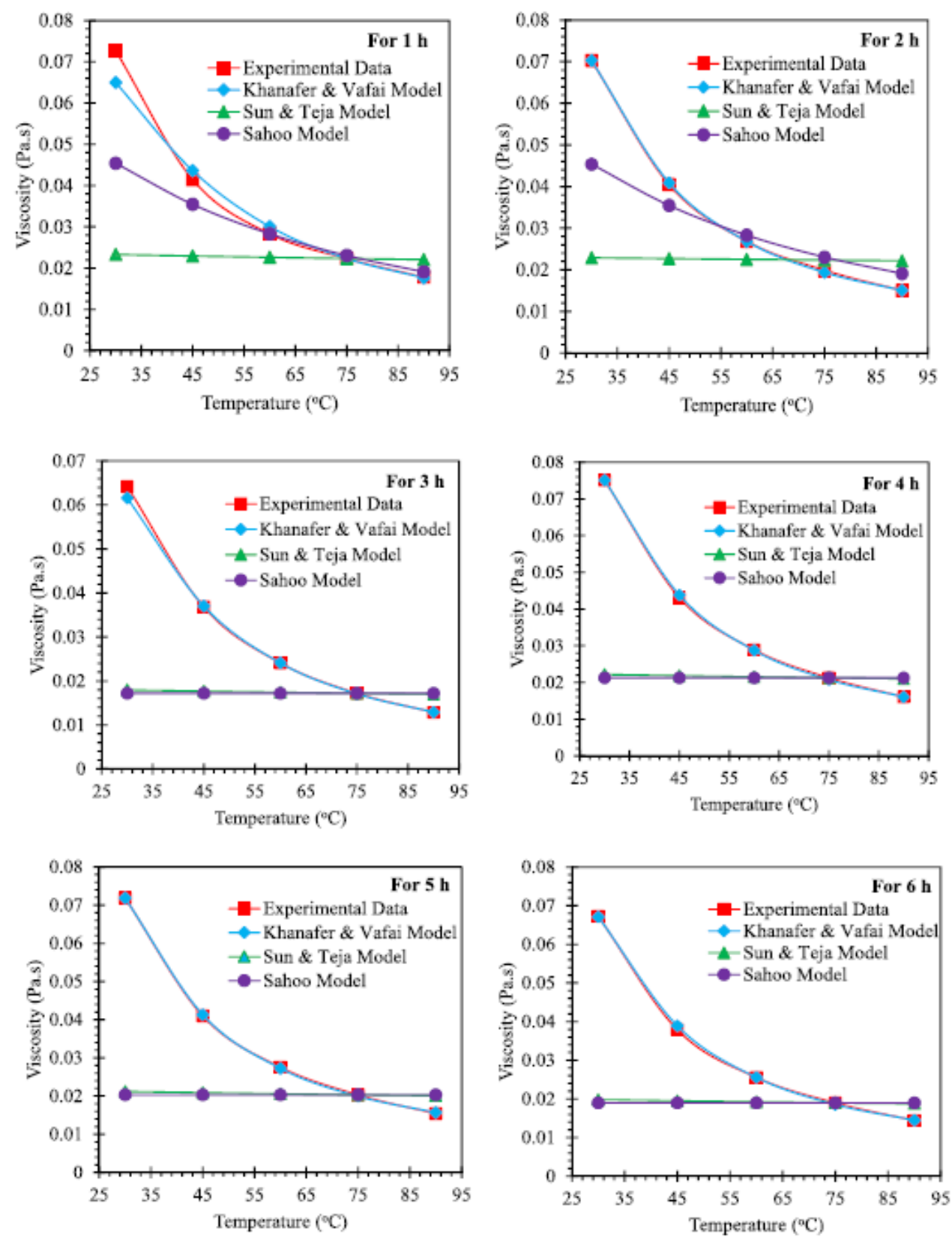

Fig. 7. Performance of proposed models for the viscosity of MWCNTs-Kapok Seed Oil based nanofluid at different ultrasonication time.

\subsection{Thermal conductivity}

The enhancement in effective thermal conductivity of thermal oils by adding the nanoparticles is the main objective towards the use of nanofluids in various heat transfer applications. Generally, the thermal conductivity is affected by the molecular vibrations and motions of free electrons while in case of nanofluids it is affected by the degree of aggregation, concentration, shape, and size of nanoparticles. The excitation and collision between nanoparticles increase with the increase in temperature which causes to increase the kinetic energy of nanoparticles and energy transfer takes place. The collision rate increases with increase in temperature due to Brownian movement of nanoparticles which is a key mechanism for the enhancement of thermal conductivity of nanofluids. (See Tables 1 and 2.) 
Table 1

Curve-fit parameters of models for the viscosity of MWCNTs-Kapok Seed Oil based nanofluid.

\begin{tabular}{|c|c|c|c|c|c|c|c|c|c|c|}
\hline \multirow[t]{2}{*}{$\mathrm{T}(\mathrm{h})$} & \multirow[t]{2}{*}{ Models } & \multicolumn{7}{|c|}{ Curve-fit parameters } & \multirow[t]{2}{*}{ AAE } & \multirow[t]{2}{*}{$\mathrm{R}^{2}$} \\
\hline & & A & B & $\mathrm{C}$ & $\mathrm{D}$ & $\mathrm{E}$ & $\mathrm{F}$ & G & & \\
\hline \multirow[t]{3}{*}{1} & Khanafer and Vafai & 0.929247 & 0.069423 & 1.338922 & 1.716072 & 160.5923 & 4.826998 & 2480.701 & 0.046042 & 0.9833 \\
\hline & Sun and Teja & 15.83115 & 0.918322 & 0 & & & & & 0.313142 & 0.8905 \\
\hline & Sahoo et al. & 0.000225 & 1590.341 & 0.126063 & & & & & 0.124701 & 0.9514 \\
\hline \multirow[t]{3}{*}{2} & Khanafer and Vafai & 0.931361 & 0.070153 & 1.342854 & 1.670544 & 134.2253 & 4.785639 & 1575.29 & 0.007965 & 0.9998 \\
\hline & Sun and Teja & 16.09069 & 1.814382 & 105.3323 & & & & & 0.375056 & 0.9009 \\
\hline & Sahoo et al. & 0.000225 & 1590.341 & 0.126063 & & & & & 0.192434 & 0.9648 \\
\hline \multirow[t]{3}{*}{3} & Khanafer and Vafai & 0.931258 & 0.069646 & 1.342641 & 1.670209 & 134.387 & 4.787466 & 1785.174 & 0.011595 & 0.9990 \\
\hline & Sun and Teja & 11.14914 & 1.751555 & 0 & & & & & 0.367519 & 0.9141 \\
\hline & Sahoo et al. & 0.012957 & 0.034622 & 0.565556 & & & & & 0.377427 & 0.9096 \\
\hline \multirow[t]{3}{*}{4} & Khanafer and Vafai & 0.931370 & 0.069537 & 1.342849 & 1.670495 & 144.3153 & 4.785303 & 1711.061 & 0.009577 & 0.9997 \\
\hline & Sun and Teja & 14.12909 & 1.825103 & 0 & & & & & 0.351942 & 0.9106 \\
\hline & Sahoo et al. & 0.015750 & 0.034623 & 0.600063 & & & & & 0.362144 & 0.9061 \\
\hline \multirow[t]{3}{*}{5} & Khanafer and Vafai & 0.931413 & 0.070153 & 1.342923 & 1.670579 & 128.3429 & 4.784433 & 1399.943 & 0.011763 & 0.9998 \\
\hline & Sun and Teja & 13.42037 & 1.813277 & 0 & & & & & 0.350896 & 0.9079 \\
\hline & Sahoo et al. & 0.015095 & 0.034623 & 0.592592 & & & & & 0.361105 & 0.9034 \\
\hline \multirow[t]{3}{*}{6} & Khanafer and Vafai & 0.922651 & 0.069664 & 1.209609 & 1.425769 & 125.5871 & 4.337048 & 1441.885 & 0.011091 & 0.9994 \\
\hline & Sun and Teja & 12.44385 & 1.795450 & 0 & & & & & 0.348036 & 0.9029 \\
\hline & Sahoo et al. & 0.014184 & 0.034623 & 0.582073 & & & & & 0.358280 & 0.8982 \\
\hline
\end{tabular}

Table 2

Curve-fit parameters of models for thermal conductivity of MWCNTs-Kapok Seed Oil based nanofluid.

\begin{tabular}{|c|c|c|c|c|c|c|c|c|c|c|c|c|c|c|}
\hline \multirow[t]{2}{*}{$\mathrm{T}(\mathrm{h})$} & \multirow[t]{2}{*}{ Correlations } & \multicolumn{11}{|c|}{ Curve-fit parameters } & \multirow[t]{2}{*}{$\mathrm{AAE}$} & \multirow[t]{2}{*}{$\mathrm{R}^{2}$} \\
\hline & & A & B & C & D & E & $\mathrm{F}$ & G & $\mathrm{H}$ & I & $\mathrm{J}$ & K & & \\
\hline \multirow[t]{4}{*}{1} & Eq. (8) & 1.043606 & 0.000086 & 0.003430 & 0.019504 & 0.013975 & 0.002530 & 0.000103 & 0.034089 & 1.717625 & 0.040700 & 1.670223 & 0.000174 & 0.9953 \\
\hline & Eq. (9) & 1.008834 & 0 & 0.004223 & 0.051902 & 0.002080 & 0.002080 & 0.007189 & 0.019300 & 0.000081 & & & 0.000177 & 1 \\
\hline & Eq. (10) & 0.564974 & 0.470481 & 0.723314 & 0.617766 & 0.273000 & 0.380460 & & & & & & 0.003741 & 0.9912 \\
\hline & Eq. (11) & 1.573546 & 0.714397 & 0.167910 & 0.069916 & 0.208156 & 0.485435 & 0.442752 & & & & & 0.005671 & 0.9953 \\
\hline \multirow[t]{4}{*}{2} & Eq. (8) & 1.051651 & 0.000084 & 0.003252 & 0.019500 & 0.013999 & 0.002530 & 0.000103 & 0.035686 & 1.719628 & 0.040700 & 1.670035 & 0.000147 & 0.9953 \\
\hline & Eq. (9) & 1.017463 & 0.000095 & 0.004070 & 0.051900 & 0.002080 & 0.002080 & 0.007189 & 0.019300 & 0.000081 & & & 0.000147 & 1 \\
\hline & Eq. (10) & 0.565613 & 0.470145 & 0.722992 & 0.617524 & 0.272950 & 0.380330 & & & & & & 0.003719 & 0.9932 \\
\hline & Eq. (11) & 1.572535 & 0.716114 & 0.167674 & 0.069919 & 0.208260 & 0.485559 & 0.442693 & & & & & 0.013309 & 0.9953 \\
\hline \multirow[t]{4}{*}{3} & Eq. (8) & 1.065993 & 0.000059 & 0.001540 & 0.019500 & 0.013999 & 0.002530 & 0.000104 & 0.035663 & 1.719947 & 0.040700 & 1.670005 & 0.001932 & 0.9946 \\
\hline & Eq. (9) & 1.021587 & 0 & 0.003849 & 0.051901 & 0.002080 & 0.002080 & 0.007190 & 0.019300 & 0.000081 & & & 0.000120 & 1 \\
\hline & Eq. (10) & 0.563629 & 0.471189 & 0.723026 & 0.617496 & 0.272956 & 0.380316 & & & & & & 0.008516 & 0.9885 \\
\hline & Eq. (11) & 1.554241 & 0.712323 & 0.170049 & 0.069957 & 0.208033 & 0.484852 & 0.442543 & & & & & 0.003629 & 0.9952 \\
\hline \multirow[t]{4}{*}{4} & Eq. (8) & 1.064940 & 0.000077 & 0.002819 & 0.019500 & 0.001400 & 0.002530 & 0.000103 & 0.035670 & 1.719976 & 0.0407 & 1.670002 & 0.000096 & 0.9951 \\
\hline & Eq. (9) & 1.028445 & 0 & 0.003553 & 0.051901 & 0.002080 & 0.002080 & 0.007190 & 0.019300 & 0.000081 & & & 0.000094 & 1 \\
\hline & Eq. (10) & 0.567149 & 0.469339 & 0.722988 & 0.617524 & 0.272950 & 0.380331 & & & & & & 0.003646 & 0.9914 \\
\hline & Eq. (11) & 1.573630 & 0.713921 & 0.168000 & 0.069916 & 0.208127 & 0.479876 & 0.437759 & & & & & 0.005380 & 0.9951 \\
\hline \multirow[t]{4}{*}{5} & Eq. (8) & 1.071862 & 0.000074 & 0.002563 & 0.019500 & 0.013999 & 0.002530 & 0.000104 & 0.035662 & 1.719821 & 0.040700 & 1.670017 & 0.000086 & 0.9950 \\
\hline & Eq. (9) & 1.034894 & 0 & 0.003299 & 0.063050 & 0.002098 & 0.002080 & 0.005050 & 0.019146 & 0.000081 & & & 0.000087 & 1 \\
\hline & Eq. (10) & 0.567259 & 0.469279 & 0.722958 & 0.617500 & 0.272956 & 0.380318 & & & & & & 0.003816 & 0.9915 \\
\hline & Eq. (11) & 1.574707 & 0.713880 & 0.167901 & 0.069913 & 0.208124 & 0.485441 & 0.442749 & & & & & 0.005405 & 0.9950 \\
\hline \multirow[t]{4}{*}{6} & Eq. (8) & 1.078658 & 0.000070 & 0.002338 & 0.019500 & 0.013999 & 0.002530 & 0.000104 & 0.035654 & 1.719938 & 0.040700 & 1.670006 & 0.000083 & 0.9949 \\
\hline & Eq. (9) & 1.041978 & 0.000014 & 0.003198 & 0.051916 & 0.002080 & 0.002080 & 0.007187 & 0.019300 & 0.000081 & & & 0.000082 & 1 \\
\hline & Eq. (10) & 0.566945 & 0.469446 & 0.723027 & 0.617524 & 0.272955 & 0.380331 & & & & & & 0.005692 & 0.9915 \\
\hline & Eq. (11) & 1.574341 & 0.713653 & 0.167980 & 0.069914 & 0.208110 & 0.485430 & 0.442752 & & & & & 0.005265 & 0.9949 \\
\hline
\end{tabular}

Typical behavior of thermal conductivity of pure oil and MWCNTs-Kapok Seed Oil nanofluid at different temperature $\left(25-65^{\circ} \mathrm{C}\right)$ and ultrasonication time $(1-6 \mathrm{~h})$ is shown in Fig. 8. The maximum thermal conductivity of pure oil and MWCNTs-Kapok Seed Oil based nanofluid found in this work are $(0.195 \mathrm{~W} / \mathrm{m} \cdot \mathrm{K})$ at $65{ }^{\circ} \mathrm{C}$ and $(0.207 \mathrm{~W} / \mathrm{m} \cdot \mathrm{K})$ at $65^{\circ} \mathrm{C}$ and $6 \mathrm{~h}$ ultrasonication time respectively. Both pure oil and nanofluid shows an increase in thermal conductivity with temperature and ultrasonication time. The tendency of nanoparticles to settle earlier in lower ultrasonication time may cause the fluctuation in the thermal conductivity as shown in Fig. 8 that lower thermal conductivity at lower ultrasonication time while higher thermal conductivity at higher ultrasonication time as the high ultrasonication time results in a stable dispersion of nanoparticles which lead to the high stability of nanofluids and that is the significant parameter in the commercialization of nanofluids for industrial applications. Similar trend found in existing experimental investigations such as functionalized alumina-thermal oil based nanofluid [84] and SiC-diathermic oilbased nanofluid [85] for temperature effect and alumina-alloy dispersed ethylene glycol based nanofluid [12] and carbon nanotubes dispersed ethylene glycol based nanofluid [86].

The enhancement in thermal conductivity and thermal conductivity ratio of MWCNTs-Kapok Seed Oil based nanofluid over different temperature and ultrasonication time is calculated using Eq. (6) and Eq. (7) [87] and shown in Fig. 9. 


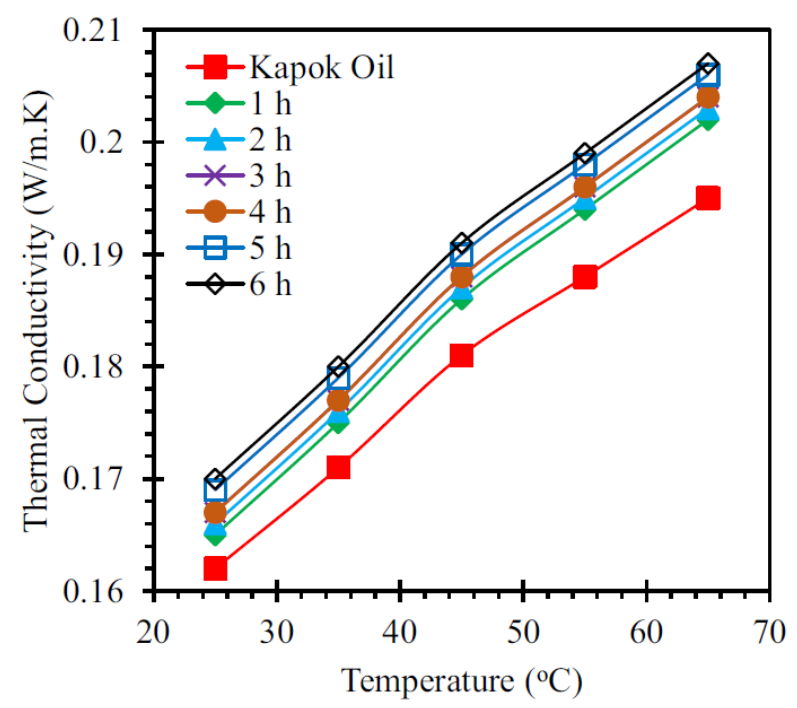

Fig. 8. Typical behavior of thermal conductivity of MWCNTs-Kapok Seed Oil nanofluid over different temperature and ultrasonication time.
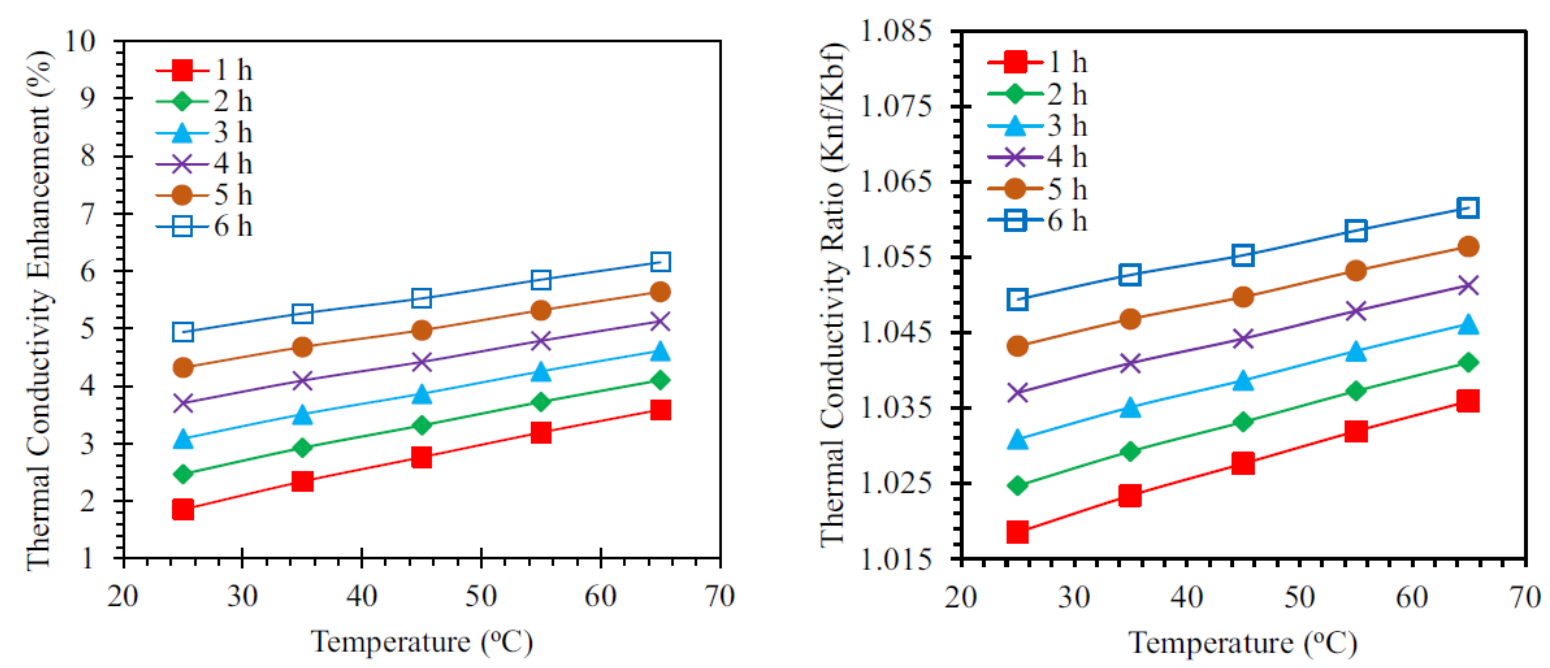

Fig. 9. Thermal conductivity enhancement and thermal conductivity ratio with temperature and ultrasonication time of MWCNT-Kapok Seed Oil based nanofluid.

$K_{n f, \text { Enhancement }}=\left(\frac{K_{n f}-K_{b f}}{K_{b f}}\right) \cdot 100$

$K_{n f, \text { Ratio }}=\left(\frac{K_{n f}}{K_{b f}}\right)$

The maximum enhancement in thermal conductivity and thermal conductivity ratio in this work is $6.1538 \%$ and 1.6015 respectively for the MWCNTs-Kapok Seed Oil based nanofluid at $65{ }^{\circ} \mathrm{C}$ and $6 \mathrm{~h}$ ultrasonication time. The typical behavior shows that both thermal conductivity enhancement and thermal conductivity ration both increase with temperature and ultrasonication time. A similar trend is reported in the literature by Ruan et al. [86] and Haris et al. [88]. The Brownian motion of nanoparticles causes a micro or nano-convection energy transfer due to increase in temperature and increase in the degree of aggregation due to ultrasonication time which leads to enhancement in thermal conductivity and thermal conductivity ration with temperature and ultrasonication time [89-93].

There are many theoretical models are available in literature such as Classical Maxwell Model [94], Hamilton-Crosser Model [95], Nan et al. Model [96], Bruggeman Model [97], Turian et al. Model [98], Patel et al. Model [99], and 
Timofeeva et al. Model [100] etc. for the prediction of thermal conductivity of nanofluids on the basis of nanoparticle concentration in nanofluid and shape of nanoparticles. However, the accurate estimation of thermal conductivity of nanofluids using above mentioned models depends upon the nanoparticle concentration and shape of nanoparticles and do not predict accurately in most of cases, due to the special properties of nanoparticles such as degree of aggregation, Brownian motion, nanoparticle structure, nanoparticle size, nanoparticle size distribution and ballistic phonon transport [101,102].

Following the study due to the lack of proper model for the accurate prediction of thermal conductivity of nanofluids based on temperature instead of nanoparticle concentration and shape of nanoparticles four suitable correlations based empirical data points proposed by Esfe et al. [103] Eqs. (8) and (9), Ilyas et al. [54] Eq. (10), and Ilyas et al. [84] Eq. (11) are suggested for this study.
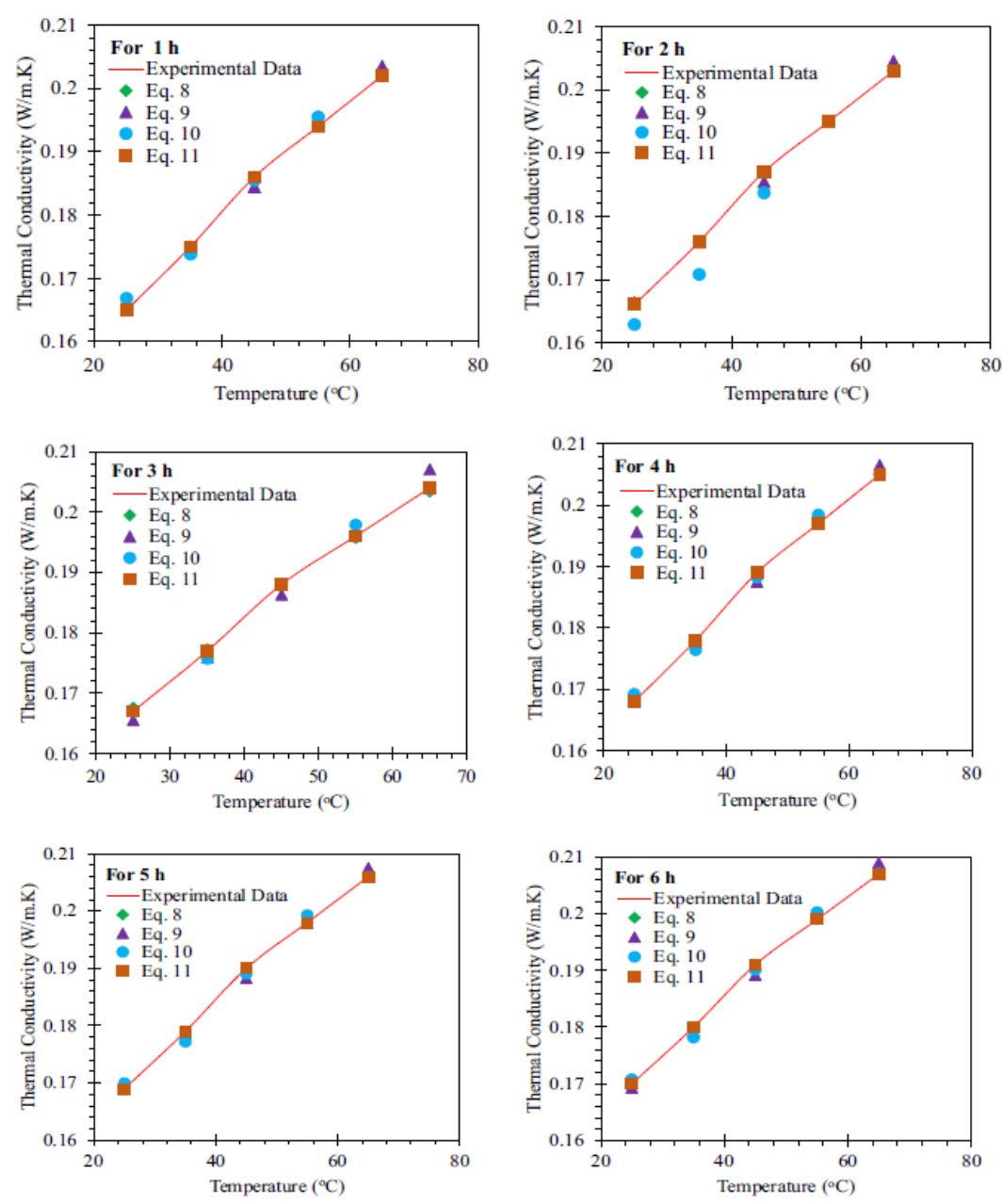

Fig. 10. Performance of proposed models for thermal conductivity of MWCNTs-Kapok Seed Oil based nanofluid at different ultrasonication time.

$K_{n f}=A+B T+C T \phi+D \phi^{2}-E \phi-F \phi^{3}-G T \phi^{2}-H \cdot \sin \left(I+J \phi^{2}-K \phi\right)$

$\frac{K_{n f}}{K_{b f}}=A-B T+C T \phi+D \phi^{2}+E \phi^{2}+F \phi^{4}-G \phi-H \phi^{3}-I T \phi^{2}$

$K_{n f}=A-B(1-\phi)+T\left[C-D(1-\phi)+\frac{E}{(1-\phi)}-\frac{F}{(1-\phi)^{2}}\right]$

$K_{n f}=A-B \ln T+C(\ln T)^{2}-D(1-\phi)-E(\ln T)(1-\phi)+\frac{F T}{1-\phi}-\frac{G T}{(1-\phi)^{2}}$ 
where $A, B, C, D, E, F, G, H, I, J$, and $K$ are curve-fit parameters which are calculated based on regression analysis and $\phi$ is the weight fraction of nanoparticles in the nanofluid. The $K_{n f}$ and $K_{b f}$ are the thermal conductivities of nanofluid and base fluid respectively. The performance of these models for the prediction of thermal conductivity of nanofluid is shown in Fig. 10.

\subsection{Rheological behavior}

The rheological flow behavior of nanofluids is the relationship between the shear stress ( $\mathrm{Pa}$ ) and shear strain rate $(1 / \mathrm{s})$. The shear stress quantifies the tangential force applied on per unit area while the shear strain accounts for the change in shear strain per unit time. The shear stress to shear strain rate ratio is known as viscosity. Based on rheological fluid behavior, the nanofluids are categorized into two major categories as Newtonian and non-Newtonian nanofluids. For Newtonian nanofluids there exist a linear relationship between the shear stress and shear strain and viscosity remains constant with shear rate while in the case on non-Newtonian nanofluids there is no linear relationship between the shear stress and shear strain and viscosity not remains constants with shear rate [104].
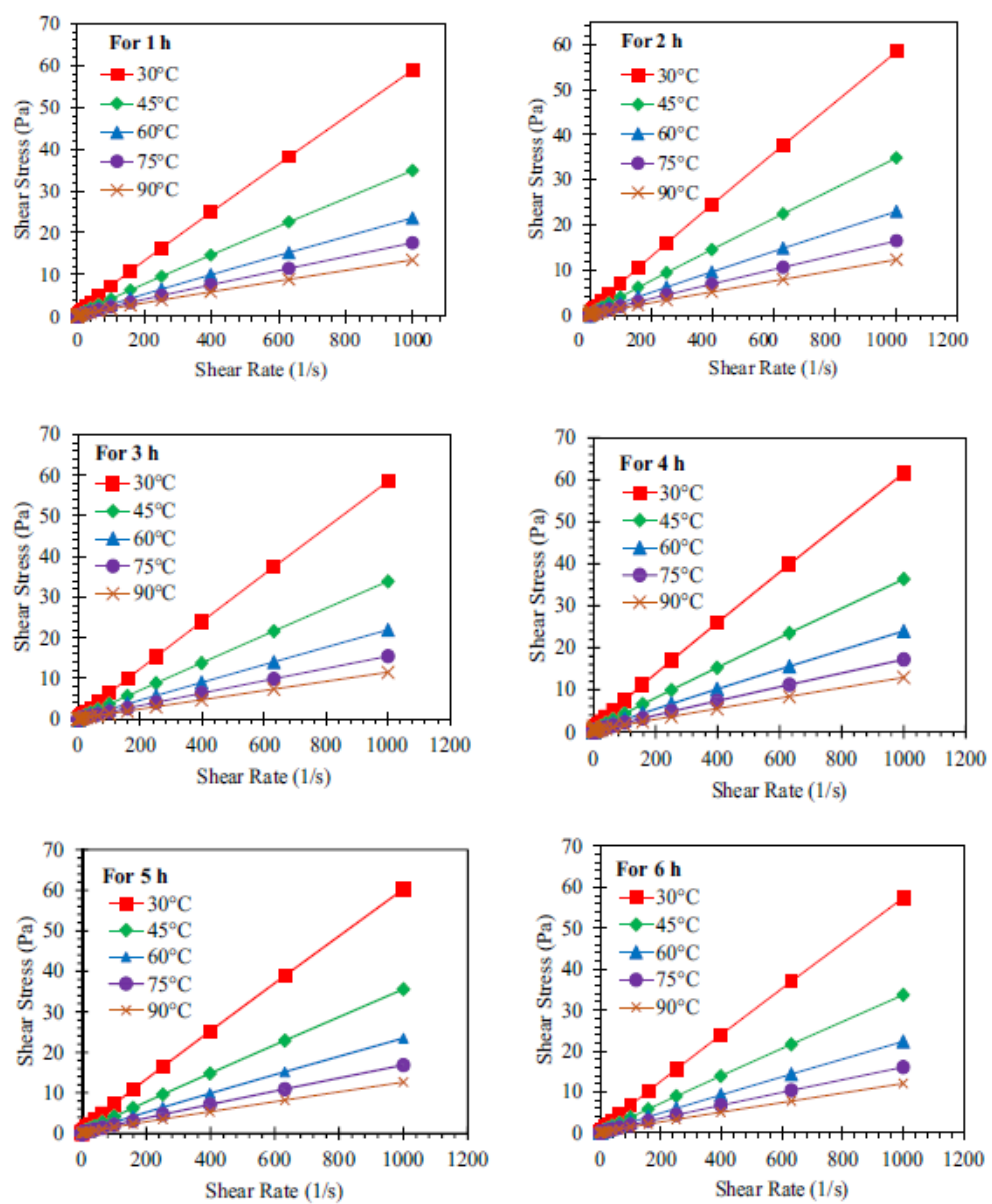

Fig. 11. Rheological behavior of MWCNTs-kapok seed oil based nanofluid at different temperature and ultrasonication time.

Rheological behavior of a nanofluid is one of the promising means to identify the characteristics of functional fluids, from which the microstructure of fluid matrix can be inferred. Rheological behavior of nanofluids significantly affects the stability and flow behavior of nanofluids in industrial applications. The rheological behavior of MWCNTs-Kapok Seed Oil based nanofluid presented in Fig. 11 at different temperature $\left(30-90^{\circ} \mathrm{C}\right)$ and ultrasonication time $(1-6 \mathrm{~h})$. The shear stress of nanofluid increase linearly with the shear rate at all temperature and ultrasonication time ranges which is similar behavior reported by Sabiha et al. [58]. The results Fig. 12 shows that at all temperature and ultrasonication time ranges, the viscosity is decreasing with increasing shear rate at various temperatures and ultrasonication times. This linear relationship between shear stress and shear rate along with decreasing viscosity with increasing shear rate trend shows that nanofluid is non-Newtonian in nature and it is an important property which revealed that non-Newtonian fluid is more useful in convective heat transfer applications which is one of the most 
important modes of heat transfer in various industrial technologies such as melting of polymers, biological solutions, tars, paints, glues and asphalts $[105,106]$. Rheological behavior is significant as it affects the viscosity which directly affects the Prandtl and Reynolds numbers as well as the pumping power of equipment. Increase in temperature is associated with the reduction in viscosity which is comparable with the trend reported by Mohammad Hemmat Esfe et al. [107]. As the temperature increases the Brownian motion of nanoparticle increase which decreases the interaction between nanoparticles and ultimately viscosity decrease [108]. This is helpful in the improvement of thermal conductivity enhancement in heat transfer applications.
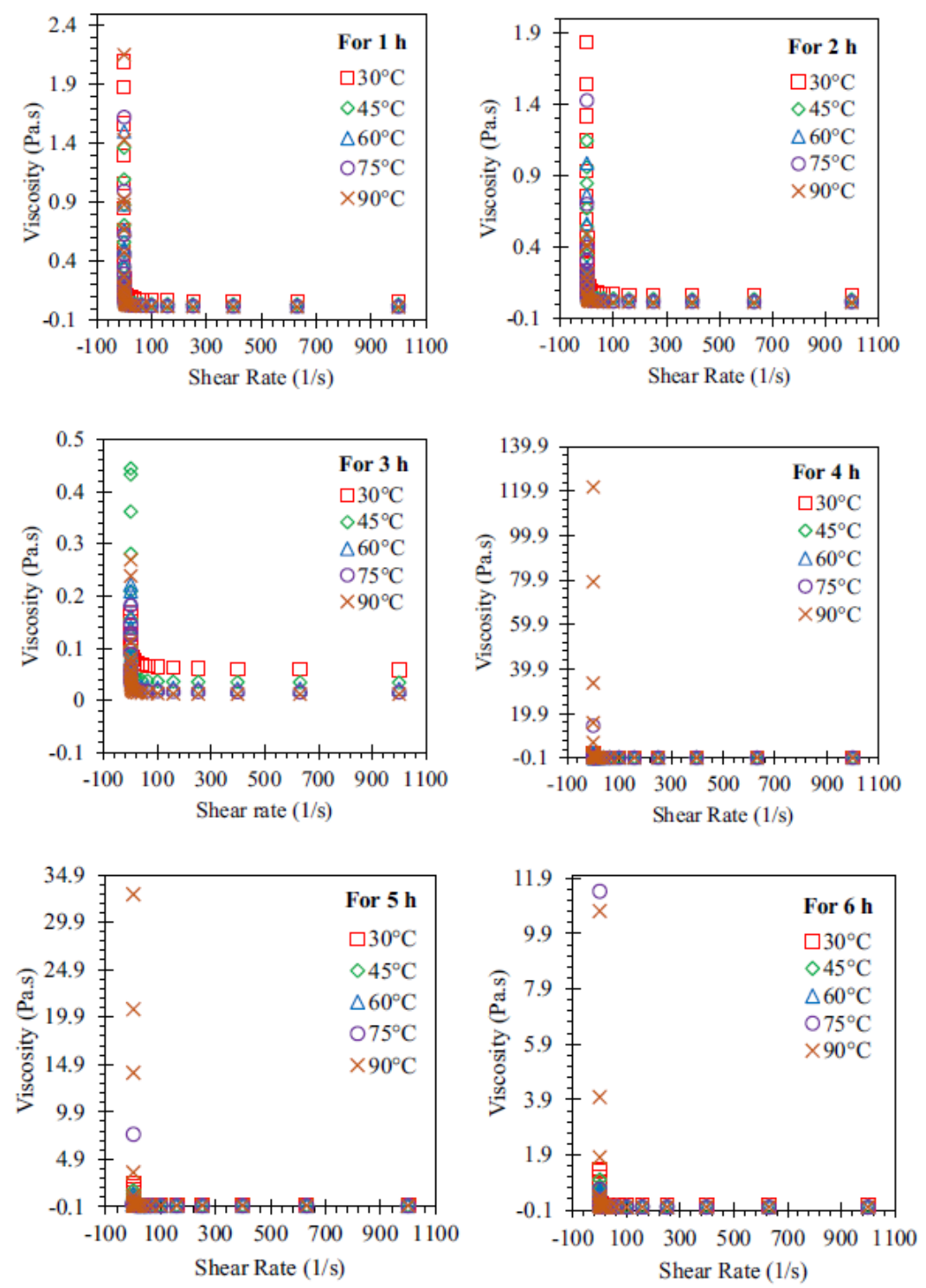

Fig. 12. Shear Thinning (Pseudo Plastic) behavior of MWCNTs-kapok seed oil based nanofluid at different temperature and ultrasonication time.

The MWCNTs-Kapok seed oil based nanofluid showed non-Newtonian and shear thinning behavior Fig. 12 at all temperatures $\left(30-90^{\circ} \mathrm{C}\right)$ and ultrasonication time ranges $(1-6 \mathrm{~h})$ as the viscosity decreases with an increase in shear rate. Such behavior of nanofluid can be expressed by the Power Law Model or Ostwald de Waele Model given in Eq. (12).

$\tau=m \gamma^{n}$

where $\tau$ is the shear stress $(\mathrm{Pa}), \gamma$ is the shear strain rate $(1 / \mathrm{s}), n$ is the power law index or flow behavior index, and $m$ is the fluid consistency index. The nanofluid with power law or flow behavior index value $(n<1)$ exhibit a non- 
Newtonian and pseudo plastic rheological behaviour which agrees with the reported researches [109-114]. More ever, the viscosity of non-Newtonian nanofluid exhibiting pseudo plastic behaviour can be expressed by Power Law Model given in Eq. (13).

$\mu=m \gamma^{n-1}$

where $\mu$ is the viscosity (Pa.s). The curve fit parameters of Power Law Model are tabulated in Table 3.

\begin{tabular}{|c|c|c|c|c|c|}
\hline $\begin{array}{l}\text { Time } \\
\text { (h) }\end{array}$ & $\begin{array}{l}\text { Temperature } \\
\left({ }^{\circ} \mathrm{C}\right)\end{array}$ & $\begin{array}{l}\text { Fluid } \\
\text { consistency } \\
\text { index }(\mathrm{m})\end{array}$ & $\begin{array}{l}\text { Flow } \\
\text { behavior } \\
\text { index }(\mathrm{n})\end{array}$ & AAE & $\mathrm{R}^{2}$ \\
\hline \multirow[t]{5}{*}{1} & 30 & 0.3106 & 0.6251 & 0.9495 & 0.2096 \\
\hline & 45 & 0.1703 & 0.5552 & 0.9202 & 0.2808 \\
\hline & 60 & 0.1134 & 0.6062 & 0.9307 & 0.2437 \\
\hline & 75 & 0.0996 & 0.6266 & 0.9348 & 0.2267 \\
\hline & 90 & 0.0886 & 0.6112 & 0.9316 & 0.3085 \\
\hline \multirow[t]{5}{*}{2} & 30 & 0.2885 & 0.6326 & 0.2061 & 0.9471 \\
\hline & 45 & 0.1609 & 0.6141 & 0.2653 & 0.9181 \\
\hline & 60 & 0.0999 & 0.6743 & 0.2465 & 0.9101 \\
\hline & 75 & 0.0915 & 0.6463 & 0.2655 & 0.9108 \\
\hline & 90 & 0.0824 & 0.1946 & 0.5776 & 0.7663 \\
\hline \multirow[t]{5}{*}{3} & 30 & 0.0944 & 0.9216 & 0.1294 & 0.7708 \\
\hline & 45 & 0.0408 & 0.9743 & 0.3610 & 0.7859 \\
\hline & 60 & 0.0217 & 0.9551 & 0.5013 & 0.7920 \\
\hline & 75 & 0.0231 & 0.9389 & 0.3088 & 0.8679 \\
\hline & 90 & 0.0363 & 0.7584 & 0.1901 & 0.8855 \\
\hline \multirow[t]{5}{*}{4} & 30 & 0.3393 & 0.6385 & 0.1972 & 0.9531 \\
\hline & 45 & 0.1446 & 0.7371 & 0.2970 & 0.8746 \\
\hline & 60 & 0.1000 & 0.6971 & 0.2763 & 0.9059 \\
\hline & 75 & 0.0947 & 0.6337 & 0.2232 & 0.7893 \\
\hline & 90 & 0.1911 & 0.0148 & 0.5561 & 0.8619 \\
\hline \multirow[t]{5}{*}{5} & 30 & 0.2858 & 0.6371 & 0.2456 & 0.9319 \\
\hline & 45 & 0.1600 & 0.5928 & 0.2831 & 0.9099 \\
\hline & 60 & 0.0999 & 0.7008 & 0.2441 & 0.9055 \\
\hline & 75 & 0.0890 & 0.6574 & 0.2527 & 0.7967 \\
\hline & 90 & 0.0420 & 0.7867 & 0.4122 & 0.8177 \\
\hline \multirow[t]{5}{*}{6} & 30 & 0.2515 & 0.6590 & 0.2350 & 0.9289 \\
\hline & 45 & 0.1305 & 0.6591 & 0.2825 & 0.8984 \\
\hline & 60 & 0.0994 & 0.6579 & 0.2680 & 0.9156 \\
\hline & 75 & 0.0826 & 0.6802 & 0.2825 & 0.7389 \\
\hline & 90 & 0.0624 & 0.6360 & 0.3555 & 0.7816 \\
\hline
\end{tabular}

The shear thinning behavior of MWCNTs-Kapok seed oil based nanofluid is due to the complex interactions between the nanoparticles (MWCNTs) and the base fluid (Kapok seed oil). Such behavior plays a significant role in fluid mechanics such as pumping power and convective heat transfer applications [115-117].

Fig. 13 shows the flowbehavior index or power-law index as a function of temperature at different ultrasonication time. The power law index decreases with an increase in ultrasonication time which means that shear thinning behavior becomes more prominent. This may be due to the high temperature and high ultrasonication leads to high agglomeration, more nanoparticle movement, and less particle sedimentation and prevents the formation of nanoclusters which results in the decrease in the power-law index or fluid behavior index. The fluid consistency index directly influenced the viscosity of nanofluid and its value decreases with increase in temperature Fig. 14 This may be due to high temperature increase the movement of nanoparticles and increase the intermolecular distances between the molecules, leading to decrease in viscosity. Due to high ultrasonication time, the Vander Waals forces between the nanoparticles and base fluid are diminished which prevent the formation of nanoclusters and nanoparticle suspension in a base fluid, leading to decrease in viscosity which is in agreement with reported research [118]. 


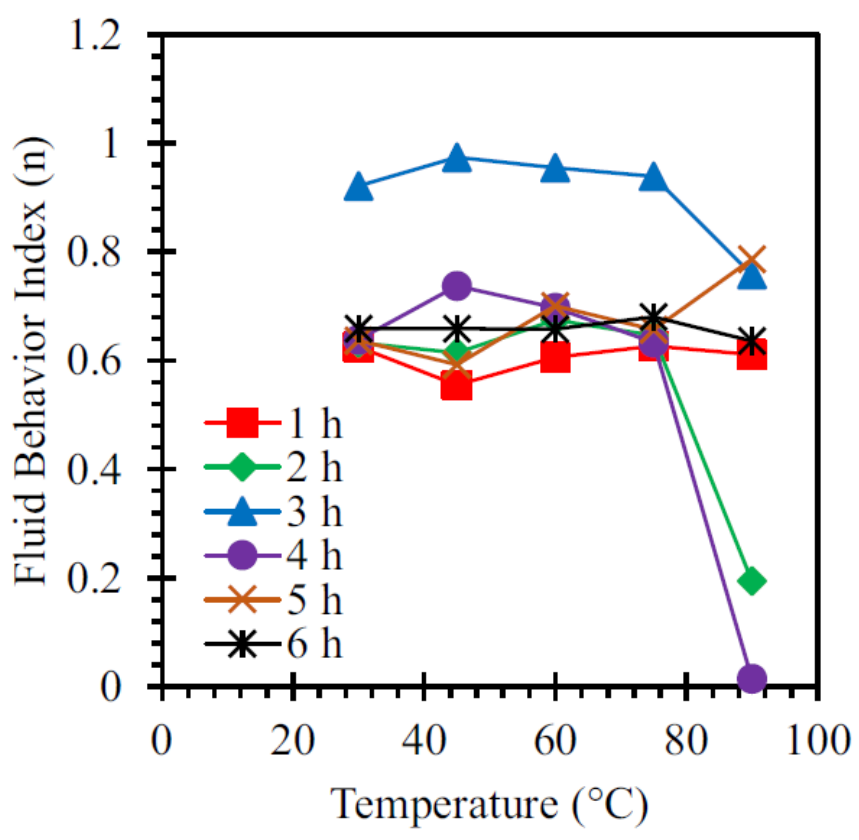

Fig. 13. Fluid behavior index as a function of temperature over different ultrasonication time ranges for non-Newtonian nanofluids.

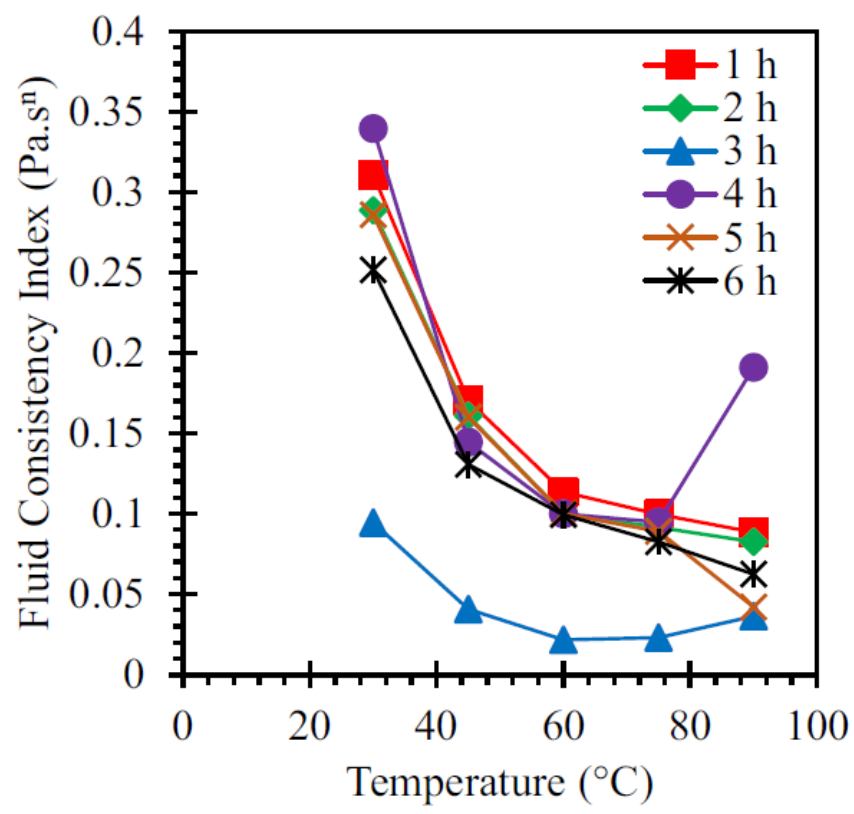

Fig. 14. Fluid consistency index as a function of temperature over different ultrasonication time ranges for non-Newtonian nanofluids.

\section{Conclusions}

In this work, MWCNTs-Kapok seed oil based nanofluid is prepared via a one-step method to investigate its thermosphysical properties over temperature $\left(30-90^{\circ} \mathrm{C}\right)$ and ultrasonication time $(1-6 \mathrm{~h})$. The results show that the viscosity decrease, and thermal conductivity increase with an increase in temperature of nanofluid. The maximum thermal conductivity enhancement of $6.1538 \%$ is observed. The experimentally measured thermo-physical properties are compared and correlated with the existing models and correlations are proposed for the prediction of thermosphysical properties. In case of viscosity, the Khanafer and Vafai Model predict the viscosity with high accuracy (AAE = $\left.0.011763, R^{2}=0.9998\right)$ while in case of thermal conductivity the Eq. (9) predict thermal conductivity with exceptional accuracy $\left(A A E=0.000082, R^{2}=1\right)$. From these experimental findings, it can be concluded that MWCNTs have wide prospects to optimize the heat transfer performance as a working fluid. The rheological behavior of MWCNTs-Kapok seed oil revealed the linear relationship between shear stress and shear strain while viscosity decrease with increase in a shear strain which means that MWCNTs-Kapok seed oil based nanofluid is non-Newtonian in nature and exhibiting shear thinning behavior. 


\section{Acknowledgement}

The authors would like to acknowledge and express their appreciation to the Research and Development Division, and the Department of Chemical Engineering at NFC Institute of Engineering and Fertilizer Research Faisalabad for their support.

\section{References}

[1] K. Anoop, S. Kabelac, T. Sundararajan, S.K. Das, Rheological and flow characteristics of nanofluids: influence of electroviscous effects and particle agglomeration, J. Appl. Phys. 106 (2009), 034909.

[2] Y. Li, S. Tung, E. Schneider, S. Xi, A review on development of nanofluid preparation and characterization, Powder Technol. 196 (2009) 89-101.

[3] S.U. Choi, J.A. Eastman, Enhancing Thermal Conductivity of Fluids with Nanoparticles, Argonne National Lab., IL (United States), 1995.

[4] S.K. Das, S.U. Choi, W. Yu, T. Pradeep, Nanofluids: Science and Technology, John Wiley \& Sons, 2007.

[5] H. Zhu, S. Liu, L. Xu, C. Zhang, Preparation, characterization and thermal properties of nanofluids, Leading Edge Nanotechnology Research Developments 2008, pp. 5-38.

[6] C. Bai, L. Wang, Constructal design of particle volume fraction in nanofluids, J. Heat Transf. 131 (2009) 112402.

[7] Y. Ding, H. Chen, L. Wang, C.-Y. Yang, Y. He, W. Yang, W.P. Lee, L. Zhang, R. Huo, Heat transfer intensification using nanofluids, Kona Powder Part. J. 25 (2007) 23-38.

[8] B. Olle, S. Bucak, T.C. Holmes, L. Bromberg, T.A. Hatton, D.I. Wang, Enhancement of oxygen mass transfer using functionalized magnetic nanoparticles, Ind. Eng. Chem. Res. 45 (2006) 4355-4363.

[9] X.-Q. Wang, A.S. Mujumdar, Heat transfer characteristics of nanofluids: a review, Int. J. Therm. Sci. 46 (2007) 1-19.

[10] D.T. Wasan, A.D. Nikolov, Spreading of nanofluids on solids, Nature 423 (2003) 156.

[11] L. Zhang, Y. Jiang, Y. Ding,M. Povey, D. York, Investigation into the antibacterial behaviour of suspensions of ZnO nanoparticles (ZnO nanofluids), J. Nanopart. Res. 9 (2007) 479-489.

[12] G. Paul, J. Philip, B. Raj, P.K. Das, I. Manna, Thermal conductivity and rheological behaviour of Al-alloy dispersed ethylene glycol based nanofluids, J. ASTM Int. 9 (2012) 1-13.

[13] N. Shalkevich, W. Escher, T. Bürgi, B. Michel, L. Si-Ahmed, D. Poulikakos, On the thermal conductivity of gold nanoparticle colloids, Langmuir 26 (2009) 663-670.

[14] C. Zhi, Y. Xu, Y. Bando, D. Golberg, Highly thermo-conductive fluid with boron nitride nanofillers, ACS Nano 5 (2011) 6571-6577.

[15] M. Yeganeh, N. Shahtahmasebi, A. Kompany, E. Goharshadi, A. Youssefi, L. Šiller, Volume fraction and temperature variations of the effective thermal conductivity of nanodiamond fluids in deionized water, Int. J. Heat Mass Transf. 53 (2010) 3186-3192.

[16] S.T. Huxtable, D.G. Cahill, S. Shenogin, L. Xue, R. Ozisik, P. Barone, M. Usrey, M.S. Strano, G. Siddons, M. Shim, Interfacial heat flow in carbon nanotube suspensions, Nat. Mater. 2 (2003) 731.

[17] J. Wang, H. Xie, Z. Xin, Y. Li, Increasing the thermal conductivity of palmitic acid by the addition of carbon nanotubes, Carbon 48 (2010) 3979-3986.

[18] B. Wang, B. Wang, P. Wei, X. Wang, W. Lou, Controlled synthesis and size dependent thermal conductivity of Fe304 magnetic nanofluids, Dalton Trans. 41 (2012) 896-899.

[19] D. Han, Z. Meng, D. Wu, C. Zhang, H. Zhu, Thermal properties of carbon black aqueous nanofluids for solar absorption, Nanoscale Res. Lett. 6 (2011) 457. 
[20] K.J. Lee, S.H. Yoon, J. Jang, Carbon nanofibers: a novel nanofiller for nanofluid applications, Small 3 (2007) 12091213.

[21] B. Wang, J. Hao, H. Li, Remarkable improvements in the stability and thermal conductivity of graphite/ethylene glycol nanofluids caused by a graphene oxide percolation structure, Dalton Trans. 42 (2013) 5866-5873.

[22] R. Zheng, J. Gao, J. Wang, G. Chen, Reversible temperature regulation of electrical and thermal conductivity using liquid-solid phase transitions, Nat. Commun. 2 (2011) 289.

[23] R. Zheng, J. Gao, J. Wang, S.-P. Feng, H. Ohtani, J. Wang, G. Chen, Thermal percolation in stable graphite suspensions, Nano Lett. 12 (2011) 188-192.

[24] N. Jha, S. Ramaprabhu, Synthesis and thermal conductivity of copper nanoparticle decorated multiwalled carbon nanotubes based nanofluids, J. Phys. Chem. C 112 (2008) 9315-9319.

[25] T.T. Baby, S. Ramaprabhu, Synthesis and nanofluid application of silver nanoparticles decorated graphene, J. Mater. Chem. 21 (2011) 9702-9709.

[26] S.S. Murshed, C.N. De Castro, Superior thermal features of carbon nanotubes-based nanofluids-a review, Renew. Sust. Energ. Rev. 37 (2014) 155-167.

[27] S. Wang, Q. Zhang, D. Yang, P. Sellin, G. Zhong, Multi-walled carbon nanotube based gas sensors for $\mathrm{NH}_{3}$ detection, Diam. Relat. Mater. 13 (2004) 1327-1332.

[28] Y. Otsubo, M. Fujiwara, M. Kouno, K. Edamura, Shear-thickening flow of suspensions of carbon nanofibers in aqueous PVA solutions, Rheol. Acta 46 (2007) 905-912.

[29] D.K. Devendiran, V.A. Amirtham, A review on preparation, characterization, properties and applications of nanofluids, Renew. Sust. Energ. Rev. 60 (2016) 21-40.

[30] A. Dalkilic, B. Küçükyıldırım, A.A. Eker, A. Çebi, S. Tapan, C. Jumpholkul, S. Wongwises, Experimental investigation on the viscosity of water-CNT and antifreeze-CNT nanofluids, Int. Commun. Heat Mass Transfer 80 (2017) 47-59.

[31] M. Xing, J. Yu, R. Wang, Experimental investigation and modelling on the thermal conductivity of CNTs based nanofluids, Int. J. Therm. Sci. 104 (2016) 404-411.

[32] M. Xing, J. Yu, R. Wang, Experimental study on the thermal conductivity enhancement of water based nanofluids using different types of carbon nanotubes, Int. J. Heat Mass Transf. 88 (2015) 609-616.

[33] M. Farbod, A. Ahangarpour, Improved thermal conductivity of Ag decorated carbon nanotubes water based nanofluids, Phys. Lett. A 380 (2016) 4044-4048.

[34] A.D. Manasrah, I.W. Almanassra, N.N. Marei, U.A. Al-Mubaiyedh, T. Laoui, M.A. Atieh, Surface modification of carbon nanotubes with copper oxide nanoparticles for heat transfer enhancement of nanofluids, RSC Adv. 8 (2018) 1791-1802.

[35] A. Amiri, R. Sadri, G. Ahmadi, B. Chew, S. Kazi, M. Shanbedi, M.S. Alehashem, Synthesis of polyethylene glycolfunctionalized multi-walled carbon nanotubes with a microwave-assisted approach for improved heat dissipation, RSC Adv. 5 (2015) 35425-35434.

[36] A. Amiri, S. Kazi, M. Shanbedi, M.N.M. Zubir, H. Yarmand, B. Chew, Transformer oil based multi-walled carbon nanotube-hexylamine coolant with optimized electrical, thermal and rheological enhancements, RSC Adv. 5 (2015) $107222-107236$.

[37] B. Wang, X. Wang, W. Lou, J. Hao, Rheological and tribological properties of ionic liquid-based nanofluids containing functionalized multi-walled carbon nanotubes, J. Phys. Chem. C 114 (2010) 8749-8754.

[38] M.P. Shevelyova, Y.U. Paulechka, G.J. Kabo, A.V. Blokhin, A.G. Kabo, T.M. Gubarevich, Physicochemical properties of imidazolium-based ionic nanofluids: density, heat capacity, and enthalpy of formation, J. Phys. Chem. C 117 (2013) 4782-4790. 
[39] S.M. Abbasi, A. Rashidi, A. Nemati, K. Arzani, The effect of functionalisation method on the stability and the thermal conductivity of nanofluid hybrids of carbon nanotubes/gamma alumina, Ceram. Int. 39 (2013) 3885-3891.

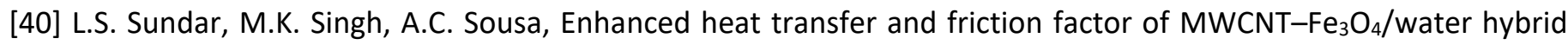
nanofluids, Int. Commun. Heat Mass Transfer 52 (2014) 73-83.

[41] Z. Han, B. Yang, S. Kim, M. Zachariah, Application of hybrid sphere/carbon nanotube particles in nanofluids, Nanotechnology 18 (2007) 105701.

[42] S. Jana, A. Salehi-Khojin, W.-H. Zhong, Enhancement of fluid thermal conductivity by the addition of single and hybrid nano-additives, Thermochim. Acta 462 (2007) 45-55.

[43] M.J. Nine, M. Batmunkh, J.-H. Kim, H.-S. Chung, H.-M. Jeong, Investigation of $\mathrm{Al}_{2} \mathrm{O}_{3}-\mathrm{MWCNTs}$ hybrid dispersion in water and their thermal characterization, J. Nanosci. Nanotechnol. 12 (2012) 4553-4559.

[44] A. Amiri, M. Shanbedi, H. Yarmand, H.K. Arzani, S. Gharehkhani, E. Montazer, R. Sadri, W. Sarsam, B. Chew, S. Kazi, Laminar convective heat transfer of hexylamine-treated MWCNTs-based turbine oil nanofluid, Energy Convers. Manag. 105 (2015) 355-367.

[45] M.-S. Liu, M.C.-C. Lin, I.-T. Huang, C.-C. Wang, Enhancement of thermal conductivity with carbon nanotube for nanofluids, Int. Commun. Heat Mass Transfer 32 (2005) 1202-1210.

[46] Y. Hwang, H. Park, J. Lee,W. Jung, Thermal conductivity and lubrication characteristics of nanofluids, Curr. Appl. Phys. 6 (2006) e67-e71.

[47] L. Chen, H. Xie, Silicon oil based multiwalled carbon nanotubes nanofluid with optimized thermal conductivity enhancement, Colloids Surf. A Physicochem. Eng. Asp. 352 (2009) 136-140.

[48] J. Shah, S. Kumar, M. Ranjan, Y. Sonvane, P. Thareja, S.K. Gupta, The effect of filler geometry on thermo-optical and rheological properties of CuO nanofluid, J. Mol. Liq. 272 (2018) 668-675.

[49] A.I. Mohammad Mahdi Heyhat, Experimental investigation on the competition between enhancement of electrical and thermal conductivities in water-based nanofluids, J. Mol. Liq. 268 (2018) (169-).

[50] G. Huminic, A. Huminic, Heat transfer capability of the hybrid nanofluids for heat transfer applications, J. Mol. Liq. 272 (2018) 857-870.

[51] D. Wen, Y. Ding, Formulation of nanofluids for natural convective heat transfer applications, Int. J. Heat Fluid Flow 26 (2005) 855-864.

[52] H.-t. Zhu, Y.-s. Lin, Y.-s. Yin, A novel one-step chemical method for preparation of copper nanofluids, J. Colloid Interface Sci. 277 (2004) 100-103.

[53] V.S. Korada, N.H.B. Hamid, Engineering Applications of Nanotechnology: From Energy to Drug Delivery, Springer, 2017.

[54] S.U. Ilyas, R. Pendyala, M. Narahari, Stability and thermal analysis of MWCNT thermal oil-based nanofluids, Colloids Surf. A Physicochem. Eng. Asp. 527 (2017) 11-22.

[55] I. Mahbubul, T.H. Chong, S. Khaleduzzaman, I. Shahrul, R. Saidur, B. Long, M. Amalina, Effect of ultrasonication duration on colloidal structure and viscosity of alumina-water nanofluid, Ind. Eng. Chem. Res. 53 (2014) 6677-6684.

[56] S.U. Ilyas, R. Pendyala, N. Marneni, Preparation, sedimentation, and agglomeration of nanofluids, Chem. Eng. Technol. 37 (2014) 2011-2021.

[57] H. Rehman,M. Batmunkh, H. Jeong, H. Chung, Sedimentation study and dispersion behavior of $\mathrm{Al}_{2} \mathrm{O}_{3}-\mathrm{H}_{2} \mathrm{O}$ nanofluids with dependence of time, Adv. Sci. Lett. 6 (2012) 96-100.

[58] M. Sabiha, R. Mostafizur, R. Saidur, S. Mekhilef, Experimental investigation on thermo physical properties of single walled carbon nanotube nanofluids, Int. J. Heat Mass Transf. 93 (2016) 862-871. 
[59] W. Azmi, K. Sharma, P. Sarma, R. Mamat, S. Anuar, V.D. Rao, Experimental determination of turbulent forced convection heat transfer and friction factor with $\mathrm{SiO}_{2}$ nanofluid, Exp. Thermal Fluid Sci. 51 (2013) 103-111.

[60] W.U. Rehman, A. Bhat, A. Suliamon, M.I. Khan, Effect of Sonication on the Stability of Nanofluids Based on the Mixture of Kapok Seeds Oil and Multi Walled Carbon Nanotubes, Key Engineering Materials, Trans Tech Publ, 2016 213-217.

[61] C. Yang, J. Mamouni, Y. Tang, L. Yang, Antimicrobial activity of single-walled carbon nanotubes: length effect, Langmuir 26 (2010) 16013-16019.

[62] W. Ma, L. Song, R. Yang, T. Zhang, Y. Zhao, L. Sun, Y. Ren, D. Liu, L. Liu, J. Shen, Directly synthesized strong, highly conducting, transparent single-walled carbon nanotube films, Nano Lett. 7 (2007) 2307-2311.

[63] L. Song, L. Ci, L. Lv, Z. Zhou, X. Yan, D. Liu, H. Yuan, Y. Gao, J.Wang, L. Liu, Direct synthesis of a macroscale singlewalled carbon nanotube non-woven material, Adv. Mater. 16 (2004) 1529-1534.

[64] A. Schierz, H. Zänker, Aqueous suspensions of carbon nanotubes: surface oxidation, colloidal stability and uranium sorption, Environ. Pollut. 157 (2009) 1088-1094.

[65] Y. Wang, Z. Iqbal, S. Mitra, Rapidly functionalized, water-dispersed carbon nanotubes at high concentration, J. Am. Chem. Soc. 128 (2006) 95-99.

[66] P.B. Murthy, A.S. Kishore, P. Surekha, Acute Toxicological Effects of Multi-walled Carbon Nanotubes (MWCNT), Carbon Nanotubes-Growth and Applications, InTech, 2011.

[67] F. Lupo, J. Rodriguez-Manzo, A. Zamudio, A. Elias, Y. Kim, T. Hayashi, M. Muramatsu, R. Kamalakaran, H. Terrones, M. Endo, Pyrolytic synthesis of long strands of large diameter single-walled carbon nanotubes at atmospheric pressure in the absence of sulphur and hydrogen, Chem. Phys. Lett. 410 (2005) 384-390.

[68] A. Barreiro, C. Kramberger, M.H. Rümmeli, A. Grüneis, D. Grimm, S. Hampel, T. Gemming, B. Büchner, A. Bachtold, T. Pichler, Control of the single-wall carbon nanotube mean diameter in sulphur promoted aerosol-assisted chemical vapour deposition, Carbon 45 (2007) 55-61.

[69] H. Hou, A.K. Schaper, F. Weller, A. Greiner, Carbon nanotubes and spheres produced by modified ferrocene pyrolysis, Chem. Mater. 14 (2002) 3990-3994.

[70] S.U. Ilyas, R. Pendyala, N. Marneni, Settling characteristics of alumina nanoparticles in ethanol-water mixtures, Applied Mechanics and Materials, Trans Tech Publ 2013, pp. 143-148.

[71] S.U. Ilyas, R. Pendyala, N. Marneni, Stability and agglomeration of alumina nanoparticles in ethanol-water mixtures, Procedia Eng. 148 (2016) 290-297.

[72] S. Ilyas, R. Pendyala, N.Marneni, Dispersion behaviour and agglomeration effects of zinc oxide nanoparticles in ethanol-water mixtures, Mater. Res. Innov. 18 (2014) (S6-179-S176-183).

[73] K. Suganthi, K. Rajan, Temperature induced changes in $\mathrm{ZnO}-$ water nanofluid: zeta potential, size distribution and viscosity profiles, Int. J. Heat Mass Transf. 55 (2012) 7969-7980.

[74] W. Yu, H. Xie, Y. Li, L. Chen, Q.Wang, Experimental investigation on the heat transfer properties of Al2O3 nanofluids using the mixture of ethylene glycol and water as base fluid, Powder Technol. 230 (2012) 14-19.

[75] R. Prasher, D. Song, J.Wang, P. Phelan,Measurements of nanofluid viscosity and its implications for thermal applications, Appl. Phys. Lett. 89 (2006) 133108.

[76] T. Wang, M. Ni, Z. Luo, C. Shou, K. Cen, Viscosity and aggregation structure of nanocolloidal dispersions, Chin. Sci. Bull. 57 (2012) 3644-3651.

[77] S.E.B. Maiga, S.J. Palm, C.T. Nguyen, G. Roy, N. Galanis, Heat transfer enhancement by using nanofluids in forced convection flows, Int. J. Heat Fluid Flow 26 (2005) 530-546. 
[78] C. Nguyen, F. Desgranges, G. Roy, N. Galanis, T. Maré, S. Boucher, H.A. Mintsa, Temperature and particle-size dependent viscosity data for water-based nanofluids-hysteresis phenomenon, Int. J. Heat Fluid Flow 28 (2007) 14921506.

[79] W.J. Tseng, K.-C. Lin, Rheology and colloidal structure of aqueous $\mathrm{TiO}_{2}$ nanoparticle suspensions, Mater. Sci. Eng. A 355 (2003) 186-192.

[80] J. Buongiorno, Convective transport in nanofluids, J. Heat Transf. 128 (2006) 240-250.

[81] K. Khanafer, K. Vafai, A critical synthesis of thermophysical characteristics of nanofluids, Int. J. Heat Mass Transf. 54 (2011) 4410-4428.

[82] T. Sun, A.S. Teja, Density, viscosity, and thermal conductivity of aqueous ethylene, diethylene, and triethylene glycolmixtures between $290 \mathrm{~K}$ and $450 \mathrm{~K}$, J. Chem. Eng. Data 48 (2003) 198-202.

[83] D.P. Kulkarni, D.K. Das, G.A. Chukwu, Temperature dependent rheological property of copper oxide nanoparticles suspension (nanofluid), J. Nanosci. Nanotechnol. 6 (2006) 1150-1154.

[84] S.U. Ilyas, R. Pendyala,M. Narahari, L. Susin, Stability, rheology and thermal analysis of functionalized aluminathermal oil-based nanofluids for advanced cooling systems, Energy Convers. Manag. 142 (2017) 215-229.

[85] X. Li, C. Zou, L. Zhou, A. Qi, Experimental study on the thermo-physical properties of diathermic oil based SiC nanofluids for high temperature applications, Int. J. Heat Mass Transf. 97 (2016) 631-637.

[86] B. Ruan, A.M. Jacobi, Ultrasonication effects on thermal and rheological properties of carbon nanotube suspensions, Nanoscale Res. Lett. 7 (2012) 127.

[87] P. Van Trinh, N.N. Anh, B.H. Thang, N.T. Hong, N.M. Hong, P.H. Khoi, P.N. Minh, P.N. Hong, Enhanced thermal conductivity of nanofluid-based ethylene glycol containing $\mathrm{Cu}$ nanoparticles decorated on a Gr-MWCNT hybrid material, RSC Adv. 7 (2017) 318-326.

[88] S. Harish, K. Ishikawa, E. Einarsson, S. Aikawa, T. Inoue, P. Zhao, M. Watanabe, S. Chiashi, J. Shiomi, S. Maruyama, Temperature dependent thermal conductivity increase of aqueous nanofluid with single walled carbon nanotube inclusion, Mater. Express 2 (2012) 213-223.

[89] P. Keblinski, R. Prasher, J. Eapen, Thermal conductance of nanofluids: is the controversy over? J. Nanopart. Res. 10 (2008) 1089-1097.

[90] J. Gao, R. Zheng, H. Ohtani, D. Zhu, G. Chen, Experimental investigation of heat conduction mechanisms in nanofluids. Clue on clustering, Nano Lett. 9 (2009) 4128-4132.

[91] W. Evans, R. Prasher, J. Fish, P. Meakin, P. Phelan, P. Keblinski, Effect of aggregation and interfacial thermal resistance on thermal conductivity of nanocomposites and colloidal nanofluids, Int. J. Heat Mass Transf. 51 (2008) 1431-1438.

[92] C. Pang, J.-Y. Jung, J.W. Lee, Y.T. Kang, Thermal conductivity measurement of methanol-based nanofluids with Al2O3 and SiO2 nanoparticles, Int. J. Heat Mass Transf. 55 (2012) 5597-5602.

[93] Y. Feng, B. Yu, P. Xu,M. Zou, The effective thermal conductivity of nanofluids based on the nanolayer and the aggregation of nanoparticles, J. Phys. D. Appl. Phys. 40 (2007) 3164.

[94] G.J. Maxwell, Colours inmetal glasses andmetal films, Philos. Trans. R. Soc. Lond. A 3 (1904) 385-420.

[95] R.L. Hamilton, O. Crosser, Thermal conductivity of heterogeneous two-component systems, Ind. Eng. Chem. Fundam. 1 (1962) 187-191.

[96] C.-W. Nan, Z. Shi, Y. Lin, A simple model for thermal conductivity of carbon nanotube-based composites, Chem. Phys. Lett. 375 (2003) 666-669.

[97] D. Bruggeman, The calculation of various physical constants of heterogeneous substances. I. The dielectric constants and conductivities of mixtures composed of isotropic substances, Ann. Phys. 416 (1935) 636-791. 
[98] R.M. Turian, D.-J. Sung, F.-L. Hsu, Thermal conductivity of granular coals, coal-water mixtures and multisolid/liquid suspensions, Fuel 70 (1991) 1157-1172.

[99] H. Patel, K. Anoop, T. Sundararajan, S.K. Das, Model for thermal conductivity of CNT-nanofluids, Bull. Mater. Sci. 31 (2008) 387-390.

[100] E.V. Timofeeva, J.L. Routbort, D. Singh, Particle shape effects on thermophysical properties of alumina nanofluids, J. Appl. Phys. 106 (2009), 014304. .

[101] P. Keblinski, S. Phillpot, S. Choi, J. Eastman, Mechanisms of heat flow in suspensions of nano-sized particles (nanofluids), Int. J. Heat Mass Transf. 45 (2002) 855-863.

[102] A. Joshi, A. Majumdar, Transient ballistic and diffusive phonon heat transport in thin films, J. Appl. Phys. 74 (1993) 31-39.

[103] M.H. Esfe, A. Karimipour,W.-M. Yan,M. Akbari, M.R. Safaei,M. Dahari, Experimental study on thermal conductivity of ethylene glycol based nanofluids containing $\mathrm{Al}_{2} \mathrm{O}_{3}$ nanoparticles, Int. J. Heat Mass Transf. 88 (2015) 728-734.

[104] A.K. Sharma, A.K. Tiwari, A.R. Dixit, Rheological behaviour of nanofluids: a review, Renew. Sust. Energ. Rev. 53 (2016) 779-791.

[105] N. Nikkam, M. Ghanbarpour, M. Saleemi, E.B. Haghighi, R. Khodabandeh, M. Muhammed, B. Palm, M.S. Toprak, Experimental investigation on thermophysical properties of copper/diethylene glycol nanofluids fabricated via microwave-assisted route, Appl. Therm. Eng. 65 (2014) 158-165.

[106] R. Ellahi, M. Raza, K. Vafai, Series solutions of non-Newtonian nanofluids with Reynolds' model and Vogel's model by means of the homotopy analysis method, Math. Comput. Model. 55 (2012) 1876-1891.

[107] M.H. Esfe, A.A.A. Arani, A study on rheological characteristics of hybrid nanolubricants containingMWCNT-TiO2 nanoparticles, J. Mol. Liq. 260 (2018) 229-236.

[108] Z. Meng, D. Han, D.Wu, H. Zhu, Q. Li, Thermal conductivities, rheological behaviors and photothermal properties of ethylene glycol-based nanofluids containing carbon black nanoparticles, Procedia Eng. 36 (2012) 521-527.

[109] M. Hojjat, S.G. Etemad, R. Bagheri, J. Thibault, Rheological characteristics of non-Newtonian nanofluids: experimental investigation, Int. Commun. Heat Mass Transfer 38 (2011) 144-148.

[110] J. Lindberg, H. Sirvio, J. Martinmaa, Rheological studies on CMC, Cellul. Chem. Technol. 21 (1987) 379-385.

[111] J. Westra, Rheology of carboxymethyl cellulose with xanthan gum properties, Macromolecules 22 (1989) 367370.

[112] K. Abdelrahim, H. Ramaswamy, High temperature/pressure rheology of carboxymethyl cellulose (CMC), Food Res. Int. 28 (1995) 285-290.

[113] D. Gómez-Díaz, J.M. Navaza, Rheology of aqueous solutions of food additives: effect of concentration, temperature and blending, J. Food Eng. 56 (2003) 387-392.

[114] F. Yaşar, H. Toğrul, N. Arslan, Flow properties of cellulose and carboxymethyl cellulose from orange peel, J. Food Eng. 81 (2007) 187-199.

[115] S. Pawar, V.K. Sunnapwar, Experimental studies on heat transfer to Newtonian and non-Newtonian fluids in helical coils with laminar and turbulent flow, Exp. Thermal Fluid Sci. 44 (2013) 792-804.

[116] D. Crespí-Llorens, P. Vicente, A. Viedma, Generalized Reynolds number and viscosity definitions for nonNewtonian fluid flow in ducts of non-uniformcross-section, Exp. Thermal Fluid Sci. 64 (2015) 125-133.

[117] Y. Lu, G. Tang, W. Tao, Experimental study of microchannel flow for non-Newtonian fluid in the presence of salt, Exp. Thermal Fluid Sci. 74 (2016) 91-99. 
[118] M. Afrand, D. Toghraie, B. Ruhani, Effects of temperature and nanoparticles concentration on rheological behavior of $\mathrm{Fe}_{3} \mathrm{O}_{4}-\mathrm{Ag} / \mathrm{EG}$ hybrid nanofluid: an experimental study, Exp. Thermal Fluid Sci. 77 (2016) 38-44. 